Is there cross-linguistic evidence for proactive cue-based retrieval interference in sentence comprehension? Eye-tracking data from English, German and Russian

Daniela Mertzen

Department of Linguistics, University of Potsdam, Potsdam, Germany

Anna Laurinavichyute

Department of Linguistics, University of Potsdam, Potsdam, Germany HSE University, Moscow, Russian Federation

Brian W. Dillon

Department of Linguistics, University of Massachusetts Amherst, USA

\title{
Ralf Engbert
}

Department of Psychology, University of Potsdam, Potsdam, Germany

Shravan Vasishth

Department of Linguistics, University of Potsdam, Potsdam, Germany

April 28, 2021

Author Note

Please send correspondence to mertzen@uni-potsdam.de. 


\begin{abstract}
Cue-based retrieval theories of sentence processing posit that long-distance dependency formation is guided by a cue-based retrieval mechanism: dependents are retrieved via retrieval cues associated with the verb. When these retrieval cues match not only a target item, but also similar items in memory, then this leads to similarity-based interference. In the majority of studies on interference, the effects may result from cue-dependent retrieval, but may also be explained by erroneous item encodings. A landmark study by Van Dyke \& McElree (2006) explicitly tested cue-based retrieval interference: retrieval cues were manipulated to match or mismatch semantically similar items that were presented proactively (prior to a target dependency). The support for interference of this type is weak, and only comes from English object cleft constructions. Our study provides a larger-scale cross-linguistic investigation of proactive cue-based retrieval interference. We present three large-sample eye-tracking studies in English, German and Russian that tested cue-based interference in the online processing of filler-gap dependencies under varying task demands. The English study finds some support for proactive cue-based interference in online dependency resolution, but only under low task demands. By contrast, the German and Russian data showed some evidence against the interference effect, suggesting that in languages with richer case marking, interference might be attenuated. Overall, our English data consolidates support for proactive interference that is cue-based and has its source at retrieval. Language-specific differences are not explicitly predicted by cue-based accounts and need further investigation.

Keywords: sentence processing; similarity-based interference; cue-based retrieval; eyetracking; Bayesian data analysis; task demands
\end{abstract}


Is there cross-linguistic evidence for proactive cue-based retrieval interference in sentence comprehension? Eye-tracking data from English, German and Russian

\section{Introduction}

Sentence comprehension requires us to rapidly form dependencies between non-adjacent words. For example, in (1) a dependency needs to be established between the verb complained and its subject the resident (Van Dyke, 2007).

(1) The resident who was living near the dangerous neighbor complained.

To successfully integrate such structurally and temporally distant sentence elements, a working memory system is required that can store partially analyzed linguistic material. Specifying these memory mechanisms that subserve dependency formation is a key task in modeling the architecture of language processing (Gibson, 2000; Lewis, 2000).

One account, the cue-based retrieval account, specifies that non-adjacent dependencies are formed using a cue-based retrieval mechanism (e.g., Lewis and Vasishth, 2005; McElree, 2000; Van Dyke, 2007; Van Dyke and Lewis, 2003; Van Dyke and McElree, 2011). Cue-based retrieval accounts broadly hold that retrieval processes are a key bottleneck in sentence comprehension: Sentence elements are encoded in memory, and these linguistic encodings are later reactivated, or retrieved from memory, when they are needed to support ongoing processing. In example (1), at the verb complained (the retrieval site), a memory query is launched to retrieve the sentence-initial noun phrase (NP) the resident from memory. This retrieval process relies on so-called retrieval cues to reactivate the target representation in memory. Cue-based theories generally assume that syntactic as well as semantic cues are used for retrieval. Simplifying somewhat, at the verb complained, the retrieval cues grammatical subject $\}$ and $\{$ animate $\}$ might be used to retrieve the target NP the resident that carries the matching grammatical role and animacy features.

A consequence of this cue-based retrieval process is similarity-based interference: the retrieval of a target item may be impeded by other items in the sentence, called distractors, which 
carry similar syntactic or semantic features as the target. In (1), neighbor is a distractor that shares the animacy feature with the target NP the resident. When a retrieval cue such as $\{$ animate $\}$ matches more than one item, this creates a cue overload. An overloaded cue impedes access to the target encoding in working memory, which creates similarity-based interference. These interference effects are reflected in increased processing times in reading studies.

There is considerable evidence for similarity-based interference in sentence comprehension. Many reading studies have investigated interference from distractors that intervene between the retrieval target and the retrieval site, as in example (1) (retroactive interference; e.g., Arnett \& Wagers, 2017; Cunnings \& Sturt, 2018; Dillon et al., 2013; Jäger et al., 2020; Keshev \& Meltzer-Asscher, 2019; Nicenboim et al., 2018; Schlueter et al., 2019; Thornton \& MacDonald, 2003; Van Dyke, 2007; Van Dyke \& Lewis, 2003). Other studies report interference from within-sentence distractors that precede the critical dependency (proactive interference; e.g., Cunnings \& Sturt, 2014; Koesterich et al., 2021; Parker \& Phillips, 2017; Van Dyke \& McElree, 2011; Wagers et al., 2009). For both pro- and retroactive interference configurations, the same underlying retrieval mechanisms are assumed, i.e., shared features of target and distractor items lead to increased processing time (e.g., Lewis \& Vasishth, 2005; McElree, 2000; Van Dyke \& McElree, 2011). Although it has been suggested that proactive interference may affect dependency formation to a lesser degree than retroactive interference (Jäger et al., 2017; Van Dyke \& McElree, 2011).

In the pre- and retroactive interference literature, a plethora of studies has shown that words encoded in memory can interfere with the processing of linguistic dependencies if they are semantically similar (e.g., Cunnings \& Sturt, 2018; Glaser et al., 2013; Gordon et al., 2001, 2004; Gordon et al., 2006; Laurinavichyute \& von der Malsburg, 2021b; Lowder \& Gordon, 2014; Rich \& Wagers, 2020; Van Dyke, 2007). Here, we focus on one line of research that investigates a special case of proactive semantic interference: interference from sentence-external items that were encoded in memory prior to reading a target dependency 
(e.g., Fedorenko et al., 2006; Gordon et al., 2002; Van Dyke et al., 2014; Van Dyke \& McElree, 2006). These studies show that sentence parsing can even be disrupted by lingustic items that are not structurally integrated. This research addresses a broad theoretical question in the sentence processing literature, namely, whether sentence parsing relies on domain-general or domain-specific memory resources (Caplan \& Waters, 1999; Just \& Carpenter, 1992). Interference from sentence-external items on real-time sentence comprehension supports a view that sentence parsing relies on general memory resources used for other cognitive tasks. While these studies have shown some support for similarity-based interference effects, it remains unclear whether there is convincing evidence for interference that unambiguously arises due to cue-overload during retrieval, i.e., cue-dependent retrieval interference.

For example, the proactive interference studies by Gordon et al. (2002) and Fedorenko et al. (2006) directly manipulated memory contents, using a dual-task paradigm that consisted of a word memorization task and a sentence reading task. In Gordon et al. (2002), participants were required to memorize either three descriptive nouns (poet, cartoonist, voter) or personal names (e.g., Joel, Greg, Andy) before reading a critical subject- or object cleft sentence. These sentences had as their subject and direct object either descriptive NPs (e.g., It was the dancer that liked the fireman/the fireman liked...), or names (e.g., It was Tony that liked Joey/Joey liked...). When the sentence-external nouns matched sentence-internal NPs in semantic category, processing times were increased. Fedorenko et al. (2006) extended the Gordon et al. (2002) findings to non-clefted subject- and object-extracted relative clause structures. Their design used a memory load of either one or three nouns. When three nouns had to be memorized, interference was greater for object than subject-extracted relative clauses. The findings in both studies indicate that extra-sentential items encoded in memory can interfere with within-sentence dependency resolution. However, the source of the interference remains unclear.

The results in both studies are compatible with cue-based retrieval accounts, as well as encoding accounts (Lewandowsky et al., 2008; Oberauer \& Kliegl, 2006). Encoding accounts 
postulate that it is not cue overload at the retrieval site but the erroneous encoding of similar linguistic items in memory that leads to interference. These erroneous encodings can result from feature loss (Oberauer \& Kliegl, 2006). If deteriorated representations of NPs in memory lead to interference, then these encoding interference effects may also be observable at the retrieval site.

A landmark study by Van Dyke and McElree (2006) explicitly tested cue-dependent retrieval interference from semantically-similar, sentence-external distractors by manipulating retrieval cues at the verb. Table 1 shows how Van Dyke and McElree (2006) adapted the Gordon et al. (2002) design to achieve this. Their memorization task had three animate nouns. This was followed by self-paced reading of object-cleft sentences. In the sentences, the critical verb (sailed/fixed) was manipulated such that the semantic retrieval cue $(\{\text { sailable }\},\{\text { fixable }\})^{1}$ matched either only the target NP the boat, or matched the target NP as well as the memory nouns table, sink, truck. Cue-based retrieval accounts predict that, if the retrieval cues at the verb cannot uniquely seek out the target NP, this creates interference due to a cue overload. Because $\{$ fixable $\}$ matches the target as well as the memory nouns, interference, reflected in a reading time slowdown, is expected at fixed compared to sailed. The design included baseline comparison 'No memory load' conditions, showing the same sentences as Memory load conditions, without presenting the memory nouns. In No load conditions, no significant reading time differences are expected. This predicted reading time pattern in Load and No load conditions would be reflected in an interaction between the factors Memory load and Interference. Only cue-based retrieval accounts predict this interaction. ${ }^{2}$ Therefore, this manipulation would show clear support for interference that has its source at retrieval:

${ }^{1}$ We do not propose that the target NPs are encoded with the lexically specific features + sailable or + drinkable. Rather, these can be viewed as placeholders for semantic cues. A principled approach to defining semantic cues is described in Smith and Vasishth (2020).

2 By comparison, encoding accounts predict no reading time differences in the Memory load conditions because retrieval cues do not play a role for encoding interference. As the same target NP and memory words are used across conditions, degraded memory encodings for these items should lead to the same amount of interference in the two conditions, i.e., no difference in reading times would be expected. It is important to note that for this design, a null result does not allow us to draw conclusions about the presence or absence of encoding interference. A null result can only tell us that there is no support for retrieval interference. 
semantic retrieval cues are used during online dependency formation, and these cues can become overloaded when there are several semantically similar items in memory.

Table 1

Example item (Van Dyke \& McElree, 2006).

\section{Memory load}

table sink truck

\section{No interference}

It was the boat that the guy who lived by the sea sailed in two sunny days.

\section{Interference}

It was the boat that the guy who lived by the sea fixed in two sunny days.

Van Dyke and McElree (2006) reported cue-based retrieval interference from extra-sentential items on within-sentence dependency resolution. However, the evidence for this effect was rather weak (significant by participants and items: $F_{1}(1,55)=4.07, p<0.04, F_{2}(1,35)=5.58$, $p<0.02$; non-significant $\min F^{\prime}$ statistic: $\left.\operatorname{minF}^{\prime}(1,90)=2.35, p=0.13\right) .{ }^{3}$ A subsequent study with the same design and stimuli did not show any evidence for this interference effect in online sentence comprehension (Van Dyke et al., 2014). Thus, there is inconclusive evidence for cue-dependent retrieval interference from sentence-external materials in online sentence comprehension. To date, the claim for this effect rests on self-paced reading data in English. Overall, while there is evidence for semantic interference effects in online sentence comprehension, it remains unclear whether those effects are driven by cue-dependent retrieval processes. The present study is motivated by this current state of evidence: we investigated proactive cue-dependent retrieval interference in filler-gap dependencies, and aimed to extend findings across languages and tasks.

\section{Motivation for the present study}

The goal of this study was to test proactive cue-based retrieval interference from extrasentential material on intra-sentential dependency resolution (henceforth 'proactive interfer-

${ }^{3}$ Significance of $\min F^{\prime}$ is required to show that an effect can be generalized over participants as well as items (Clark, 1973). 
ence'), using a dual-task paradigm (Van Dyke \& McElree, 2006). This is important because the Van Dyke and McElree (2006) manipulation explicitly tested for cue-based retrieval interference, excluding encoding interference as a possible alternative explanation. Studying interference effects in such a paradigm is thus key in determining the role that cue-dependent retrieval interference plays in the processing of linguistic dependencies. Support for cueoverload due to sentence-external distractors would strengthen cue-based accounts which posit that a cue-based retrieval mechanism guides dependency formation during real-time sentence comprehension. Specifically, this effect would point to a retrieval mechanism that is not constrained to the sentence context, but that erroneously considers extraneous linguistic items as retrieval targets.

Re-investigation of proactive interference. The reason for the inconclusive findings in Van Dyke and McElree (2006) and Van Dyke et al. (2014) could be that the phenomenon under investigation exhibits only subtle effects. This is likely, given the results of Jäger et al. (2017) who derived quantitative estimates by conducting a meta-analysis of published studies on similarity-based interference effects in sentence comprehension. For non-agreement subject-verb dependencies, they showed an interference effect that lies between 2 and 28 ms. ${ }^{4}$ Small effects like similarity-based interference can remain undetected if tested with participant sample sizes routinely used in experimental psycholinguistics (e.g., Jäger et al., 2017; Vasishth et al., 2018). Prospective statistical power (i.e., the probability of detecting an effect of a certain magnitude in a planned experiment) is low for interference effects with standard participant sample sizes of 40-60 subjects (Jäger et al., 2017). Figure 1 shows that even with a participant sample size of 120 , one can end up in a low power scenario when investigating small effects.

\footnotetext{
4 All self-paced reading and eye-tracking (first-pass reading times) experiments from Van Dyke and Lewis (2003), Van Dyke and McElree (2006), Van Dyke (2007) and Van Dyke and McElree (2011) entered the meta-analysis for non-agreement subject-verb dependencies. Of those studies, only the Van Dyke and McElree (2006) study used a dual-task paradigm with sentence-external distractors. The attentional demands of this task are quite different from a common reading task. However, these studies investigated non-agreement subject-verb dependencies, and the effect magnitudes from these studies are relatively comparable.
} 


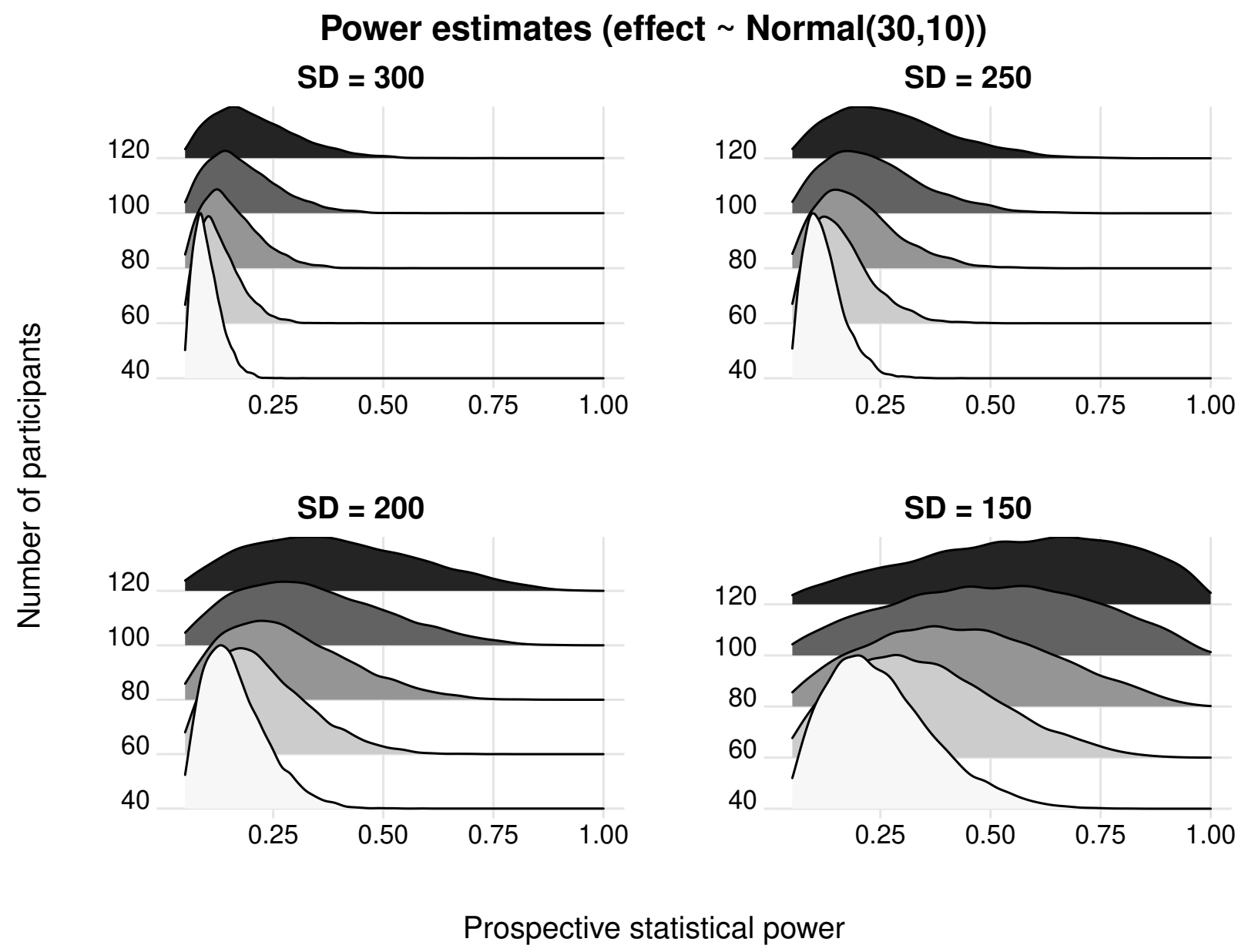

Figure 1. Power estimates for an effect size $\mathcal{N}(30,10)$ assuming various residual standard deviations (SD) $(300,250,200,150)$ for a different number of participants $(40,60,80,100$, 120). Different shadings are merely for better distinguishability. The figure is adapted from Vasishth (2019).

Low power studies lead to significant effects that are greatly overestimated (Type M (Magnitude) error; Gelman and Carlin, 2014). The interference effect reported in the Van Dyke and McElree (2006) study with sample size 56 could be such an inflated estimate (for the critical interaction: $41 \mathrm{~ms}$ with SE $20 \mathrm{~ms}$ ). There are several large-sample studies in the psycholinguistic literature that suggest that inflated estimates from underpowered studies may not be replicable. These studies re-investigated various psycholinguistic phenomena and were not able to replicate the original effects (e.g., Nicenboim et al., 2020; Nieuwland et al., 2018; Vasishth et al., 2018). The current study also aimed for a large participant sample size to obtain a precise estimate of the proactive interference effect. 
A cross-linguistic investigation of proactive interference. Similarity-based interference in sentence comprehension has been studied in a variety of languages (e.g., Chinese: Jäger et al., 2015; Hebrew: Ness and Meltzer-Asscher, 2017; Hindi: Vasishth and Lewis, 2006; Spanish: Lago et al., 2015; German, Russian: Laurinavichyute et al., 2017). However, the majority of research has focused on English, including the work on proactive interference from extra-sentential distractors (e.g., Cunnings \& Felser, 2013; Cunnings \& Sturt, 2014, 2018; Dillon et al., 2013; Sturt, 2003; Van Dyke, 2007; Van Dyke \& Lewis, 2003; Van Dyke \& McElree, 2006, 2011). If cue-based parsing mechanisms are an integral part of human language processing, as posited by cue-based theories, then proactive interference should be observable not only in English but cross-linguistically.

The current study investigates proactive interference in English, as well as German and Russian. Both German and Russian have richer morphological marking on nouns, in the form of overt nominal case marking and gender, compared to English. The overt case marking may make items in memory more easily distinguishable. Specifically, case marking on the retrieval target could make the target more distinguishable from the distractors, and consequently reduce interference (Hartsuiker et al., 2003; Nicol and Antón-Méndez, 2009, but cf. Avetisyan et al., 2020). On the other hand, if case marking does not play a role, then proactive interference effects should be of the same magnitude across languages.

Proactive interference under different processing depths. The similarity-based interference prediction is contingent on a simple but important assumption that is implicit in cue-based retrieval theories: That all syntactic dependencies are resolved during real-time processing. However, another sentence processing theory, good-enough processing, assumes that syntactic dependencies are not always resolved, but can remain underspecified (Ferreira et al., 2002). A question that has not been addressed in the interference literature is whether proactive interference effects are also observable if readers only superficially process the linguistic configurations under investigation. Our study explored this question.

There is some support for the hypothesis that a less demanding task (simple vs. more complex 
comprehension questions) will lead comprehenders to underspecify certain syntactic relations. So far, this has been shown only for relative clause attachment ambiguities (for English, see Swets et al., 2008; for German, see Logačev and Vasishth, 2016). If a simple task leads to underspecification of syntactic relations, the findings on relative clause attachment ambiguities may generalize to other linguistic dependencies. If superficial processing can be induced by a simple task, then it would be expected that proactive interference effects are smaller in magnitude than under 'deep' processing, or the effects may disappear altogether.

\section{The current study}

To test cue-based retrieval theories' prediction of proactive interference, we implemented the dual-task paradigm (Van Dyke \& McElree, 2006), using eye-tracking, in English, German and Russian. For each language, we tested two versions of the experiment. In one version, items were followed by complex comprehension questions to induce deep processing. In another version, the same participants saw new items that were followed by simple comprehension questions, inducing superficial processing. Each participant saw the two experiment versions one to three weeks apart. A summary of the experiments is shown in Table 2.

\begin{tabular}{|c|c|c|c|c|}
\hline $\begin{array}{l}\text { Study } \\
\text { language }\end{array}$ & $\begin{array}{l}\text { Experiment } \\
\text { version }\end{array}$ & $\begin{array}{l}\text { Tested } \\
\text { subjects }\end{array}$ & $\begin{array}{l}\text { Number } \\
\text { of items }\end{array}$ & $\begin{array}{l}\text { Factors } \\
2 \times 2 \text { design }\end{array}$ \\
\hline \multirow{2}{*}{ English } & Complex & \multirow{2}{*}{74} & 40 & Load, Interference \\
\hline & Simple & & 40 & Load, Interference \\
\hline \multirow{2}{*}{ German } & Complex & \multirow{2}{*}{122} & 40 & Load, Interference \\
\hline & Simple & & 40 & Load, Interference \\
\hline \multirow{2}{*}{ Russian } & Complex & \multirow{2}{*}{120} & 40 & Load, Interference \\
\hline & Simple & & 40 & Load, Interference \\
\hline
\end{tabular}

Table 2

Summary of the experiments testing proactive interference. For each language, depth of processing was manipulated through question complexity across two experiment versions. One version had complex comprehension questions (deep processing), and the other version had simple comprehension questions (superficial processing). The same participants saw both experiment versions (in randomized order) one to three weeks apart. Within each experiment version, we tested for the expected Load $\times$ Interference interaction. 


\section{Experimental design and materials}

The Memory load $\times$ Interference manipulation. Our experiments used a $2 \times 2$ fullycrossed factorial design with the factors Memory load (Load, No load) and Interference (No interference, Interference), previously implemented by Van Dyke and McElree (2006). Both factors are within-subjects, within-items manipulations.

One difference between the Van Dyke and McElree (2006) study and our study is that Van Dyke and McElree (2006) tested object-cleft sentences whereas our study uses non-clefted structures with two embedded relative clauses. In our materials, the target object is not in linguistic focus, whereas the clefted object retrieval targets in Van Dyke and McElree (2006) are. Here, focus describes the emphasis or prominence that is ascribed to certain sentence constituents by the syntactic structure (Chomsky, 1971). Psycholinguistic research has shown that items in focus have more distinctive memory representations (Birch \& Rayner, 1997; Ward \& Sturt, 2007). This may reduce the magnitude of an interference effect. Thus, we expected that non-clefted stimuli may be advantageous to detect the predicted effect.

Table 3 shows English example items for the complex (3A) and the simple (3B) experiment version. All sentences had two embedded relative clauses, the outer relative clause being an object-relative clause, the most embedded relative clause being a subject-relative clause. Multiple center-embedded sentences can be read like a list of unrelated words and reduce comprehension (e.g., see Miller, 1962; Miller and Chomsky, 1963). To avoid 'list-like' sentences (such as 'NP1 NP2 NP3 VP3 VP2 VP1'), and to increase the naturalness of the sentences, a prepositional- or an adverbial phrase was added before the matrix-clause verb.

In $(3 \mathrm{~A})$, the critical dependency is between the relative clause verb sailed/fixed and its object NP The boat. The Load conditions present a list of three concrete, inanimate, singular nouns. In the non-interfering Load condition, the memory nouns table, sink and truck are not plausible objects of the critical verb (sailed). By contrast, in the interfering Load condition, they are plausible objects of the critical verb (fixed). The sentences in the No load conditions were identical to the sentences in the Load conditions. Here, no memory nouns were shown. 
Table 3

English example items.

A) 'Complex' version:

Memory load: table sink truck

No interference

The boat that the guy who lived by the sea sailed in the morning was very old.

Interference

The boat that the guy who lived by the sea fixed in the morning was very old.

No memory load:

No interference

The boat that the guy who lived by the sea sailed in the morning was very old.

Interference

The boat that the guy who lived by the sea fixed in the morning was very old.

'Complex' question: 'Did the guy live by the sea?'

B) 'Simple' version:

Memory load: car scooter motorcycle

\section{No interference}

The plane that the pilot who returned from the Seychelles landed during the storm was pretty unreliable.

Interference

The plane that the pilot who returned from the Seychelles crashed during the storm was pretty unreliable.

No memory load:

No interference

The plane that the pilot who returned from the Seychelles landed during the storm was pretty unreliable.

Interference

The plane that the pilot who returned from the Seychelles crashed during the storm was pretty unreliable.

'Simple' question: 'Was a pilot mentioned in this sentence?' 
In our study, experimental items were followed by yes-or-no comprehension questions (with a 50:50 'yes-to-no' ratio). The complex experiment version used 40 experimental items with 90 filler items, and the simple version had 40 new experimental and 90 new filler items. German and Russian example sentences, and filler sentences are described in Appendix A. All items can be found in the supplementary materials (https://osf.io/qrcmv).

Plausibility ratings of the stimuli. For all three languages, a plausibility rating task established that the target NP (e.g., the boat) was a plausible object of the RC verb (e.g., sailed and fixed) in the No interference and in the Interference conditions. The task also established that the distracting memory nouns (e.g., table, sink, truck) had a higher plausibility rating in the Interference conditions (with fixed) compared to the No interference conditions (with sailed).

Plausibility was rated for all 80 items in each language, 40 from the complex and 40 from the simple experiment version. For this rating task, eight conditions were created that combined the critical verb (e.g., sailed or fixed) with either the target (e.g., the boat) or one of the three distractor nouns (e.g., table/sink/truck). This resulted in the eight simple sentences in Example 2. Half of the items had a feminine personal subject pronoun, and half of the items a masculine one.

These experiments were run online, using Ibex Farm (https://spellout.net/ibexfarm/). Participants who did not take part in the main study were asked to rate the plausibility of the items on a scale from ' 1 ' (very implausible) to '7' (very plausible).

(2) a. He fixed the boat.

b. He fixed the table.

c. He fixed the sink.

d. He fixed the truck.

e. He sailed the boat.

f. He sailed the table. 
g. He sailed the sink.

h. He sailed the truck.

It was expected that conditions a-e would receive higher plausibility ratings than f-h. Figure 2 shows the estimated probabilities for each of the seven rating choices in each condition. To estimate the probabilities, we fit Bayesian cumulative models in brms (Bürkner, 2017; Bürkner and Vuorre, 2019; see supplementary materials). Overall, the pattern is as expected: each language shows high plausibility ratings for a-e, i.e., the verb-target combinations (fixed/sailed the boat) and the verb-plausible distractor combinations (fixed the table/sink/truck). By contrast, lower plausibility ratings are observed in f-h, i.e., the verb-implausible distractor combination (sailed the table/sink/truck).

The depth of processing manipulation. Depth of processing was manipulated through comprehension question complexity in two experiment versions. In one version, the questions were relatively complex, while in the other version, the questions were simple. Depth of processing was implemented as a within-subjects, between-items manipulation.

Complex version. In this experiment version, complex comprehension questions induced deep processing. Here, complex refers to questions that required the reader to resolve the dependencies in the sentence. One half of the questions targeted the non-critical, most embedded relative clause (RC) (see Table 3A). The other half of the questions targeted the main clause subject-verb dependency, e.g., 'Was it the boat that was old?'

Simple version. In this version, simple questions induced superficial processing because they did not require participants to resolve within-sentence dependencies. These questions targeted non-critical NPs in the sentence (Table 3B).

English vs. German and Russian materials. Figure 3 shows schematic example sentences with memory nouns in the Load conditions for each language. In the non-interfering Load condition (a), only the sentence-initial target NP but not the memory nouns match the semantic cue of the verb (e.g., + sailable, +drinkable, or +diagnosable). In the interfering Load condition (b), the target NP as well as the memory nouns match the semantic cue at 

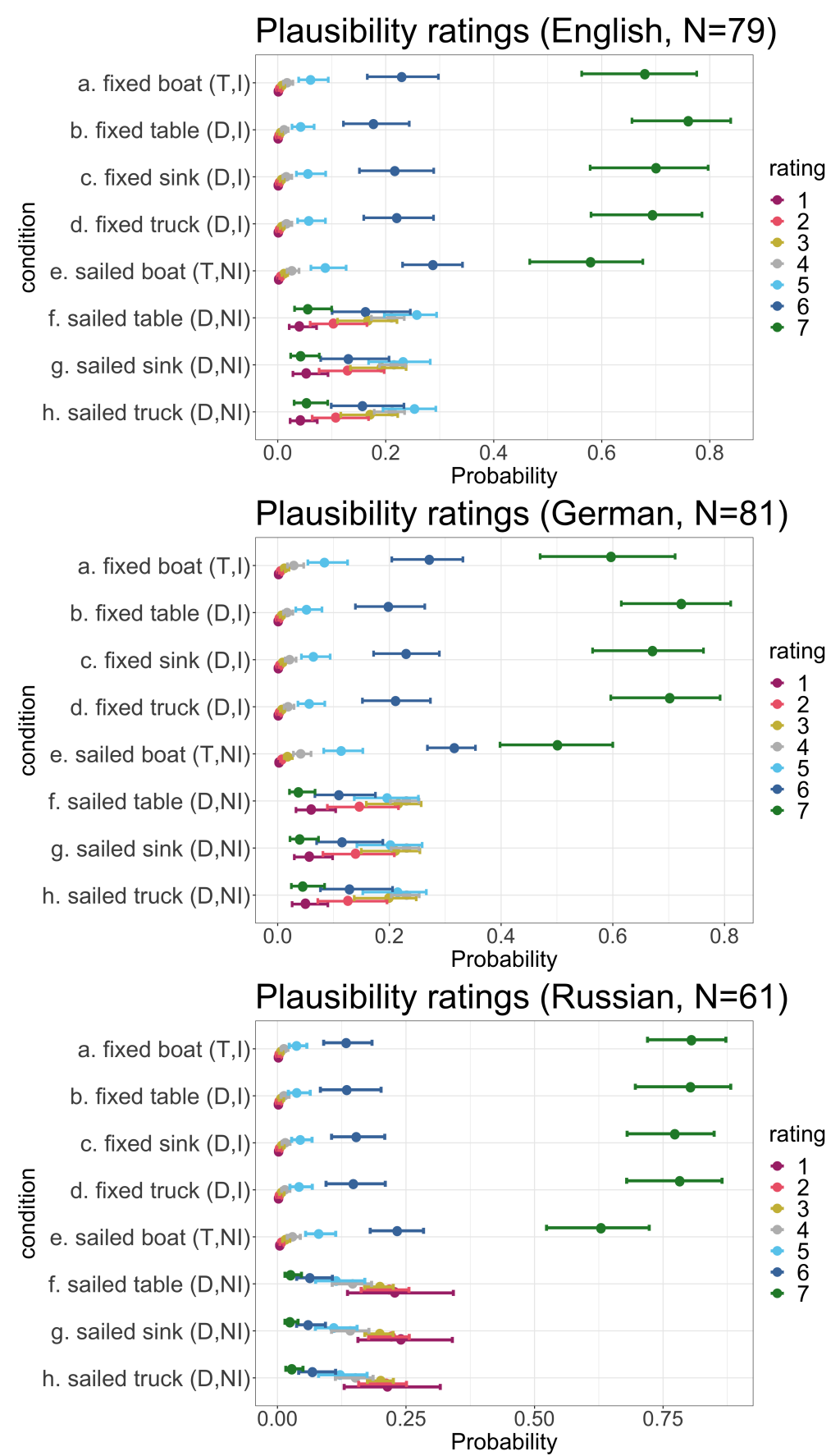

Figure 2. Plausibility ratings results for the items used in English, German and Russian. Shown are the estimates (posterior means with $95 \%$ credible intervals) of the probability of the plausibility rating in each condition. ' 1 ' $=$ very implausible, ' 7 ' = very plausible. $\mathrm{T}=$ target, $\mathrm{D}=$ distractor, $\mathrm{I}=$ Interference, $\mathrm{NI}=$ No interference. For ease of interpretability, we use the English condition labels for all three languages. 
the verb $(+$ fixable, + smellable, or +discoverable $)$. In the interfering Load condition, this should result in an overloaded semantic cue.

In the English sentences, the target NP and the complementizer that are not overtly marked for case. By contrast, in German and Russian, the target NP and relative pronoun have overt case marking. The relative pronoun, which is the target of the object-retrieval, is marked for accusative case. If the relative pronoun is accessed for the object-retrieval, an additional assumption has to be made: that the semantic features are accessible at the relative pronoun. If case serves as an additional retrieval cue in German and Russian, this should lead to greater distinguishability of the retrieval target. More distinguishable items in memory may then lead to a smaller interference effect, compared with English.

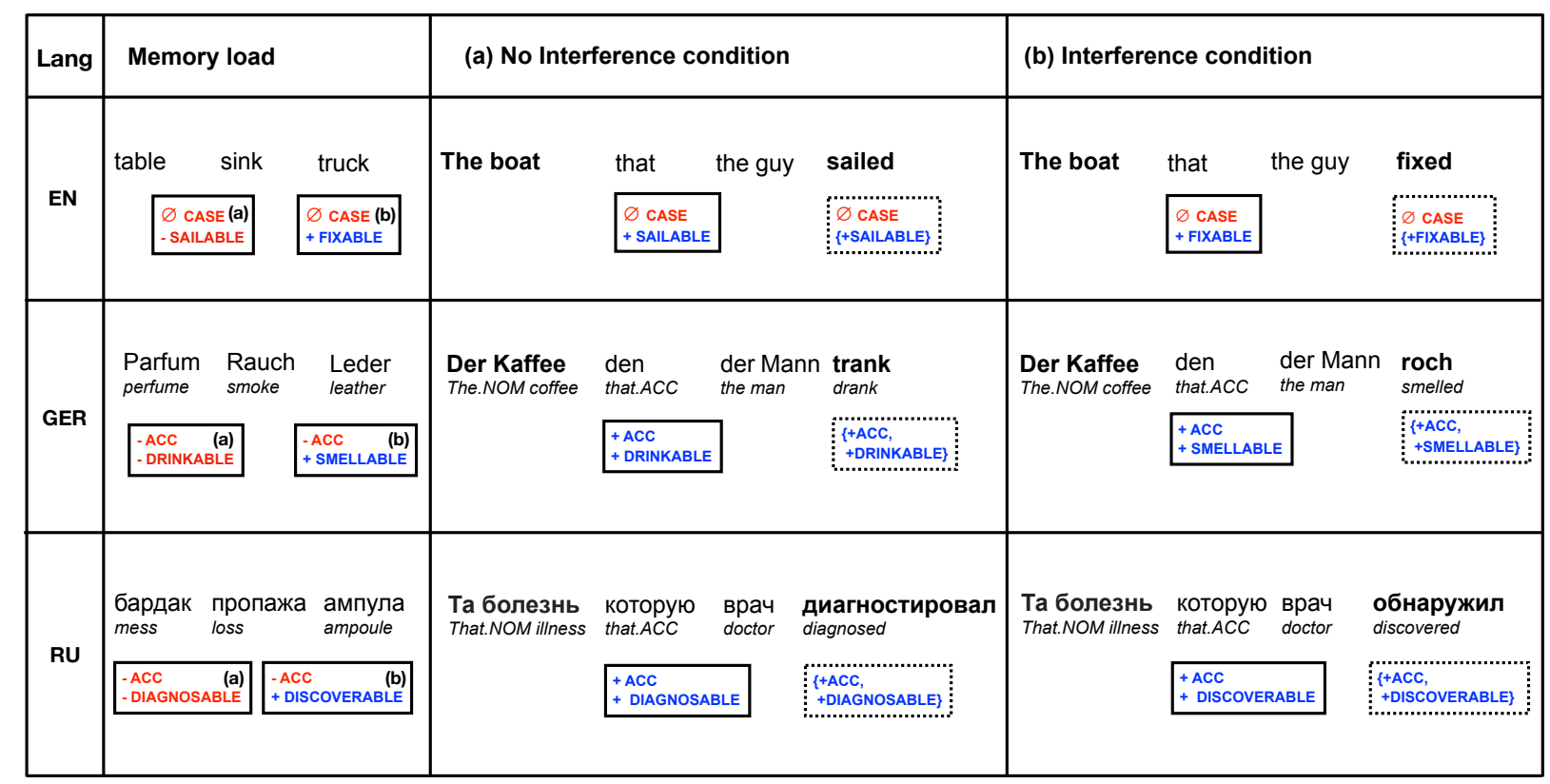

Figure 3. Example stimuli (schematic) for the English, German and Russian experiment.

Participants. All participants were native speakers of the tested language-English, German or Russian — with normal or corrected-to-normal vision and no history of language- or reading disorders.

An overview of the participant profiles is shown in Table 4. Some participants were not able to take part in the second part of the study. We excluded participants who did not have the 
tested language as their native language, who reported language disorders, and participants with poor calibration due to pupil loss. In addition, we excluded individual trials where the fixation sequence was disturbed by external influences.

The participant sample sizes resulted from collecting data until we reached a relatively precise uncertainty interval for the effect of interest (in total fixation times), i.e., an interval of width $\leq 40 \mathrm{~ms}$ ('stopping rule', Kruschke, 2015). For English, due to logistical reasons, data collection stopped when we reached a $40 \mathrm{~ms}$ interval. For both German and Russian we obtained more precise estimates of the effect, because we were able to test up to 120 participants.

\begin{tabular}{|c|c|c|c|c|c|c|}
\hline Study & $\begin{array}{l}\text { Analyzed } \\
\text { subjects }\end{array}$ & $\begin{array}{l}\text { Subject } \\
\text { profile }\end{array}$ & $\begin{array}{l}\text { Mean age } \\
\text { (range) }\end{array}$ & $\begin{array}{l}\text { Gender } \\
(\%)\end{array}$ & $\begin{array}{l}\text { Recruitment; data } \\
\text { collection location }\end{array}$ & $\begin{array}{l}\text { Reimbur- } \\
\text { sement }\end{array}$ \\
\hline English & $\begin{array}{l}66 \text { (complex) } \\
65 \text { (simple) }\end{array}$ & undergrad & $20(18-27)$ & $\begin{array}{l}\text { F: } 66 \\
\text { M: } 26 \\
\text { NB: } 8\end{array}$ & $\begin{array}{l}\text { Linguistics \& Psycho- } \\
\text { logical and Brain Sci- } \\
\text { ences pool, posters; } \\
\text { UMass Amherst, USA }\end{array}$ & $\begin{array}{l}30 \text { USD or } \\
\text { course credit }\end{array}$ \\
\hline German & $\begin{array}{l}119 \text { (complex) } \\
122 \text { (simple) }\end{array}$ & undergrad & $25(18-41)$ & $\begin{array}{l}\text { F: } 75 \\
\text { M: } 25\end{array}$ & $\begin{array}{lr}\text { Cognitive } & \text { Sciences } \\
\text { participant } & \text { pool; } \\
\text { Potsdam } & \text { University, } \\
\text { Germany } & \end{array}$ & $\begin{array}{l}30 \text { Euro or } \\
\text { course credit }\end{array}$ \\
\hline Russian & $\begin{array}{l}100 \text { (complex) } \\
109 \text { (simple) }\end{array}$ & undergrad & $22(18-55)$ & $\begin{array}{l}\text { F: } 55 \\
\text { M: } 45\end{array}$ & $\begin{array}{l}\text { Social media, word } \\
\text { of mouth; Higher } \\
\text { School of Economics, } \\
\text { Moscow, Russia }\end{array}$ & $\begin{array}{l}\text { course credit } \\
\text { or interested } \\
\text { volunteers }\end{array}$ \\
\hline
\end{tabular}

Table 4

Shown is a summary of the participant profiles for the English, German and Russian experiments. Undergrad means that participants were predominantly undergraduate students. $F=$ female, $M=$ male, $N B=$ nonbinary.

Procedure. Each participants saw both experiment versions (complex or simple) that were shown in two sessions, seven to 21 days apart. The presentation order of the two versions was randomized.

In each session, after giving informed consent, participants read the study instructions which specified that both the reading and the recall task should be paid close attention to. The 
participants were seated in front of a presentation monitor, with their head in a chin- and head rest to minimize head movements. For monocular tracking of the right eye, we used a tower-mounted EyeLink 1000 (Plus) eye-tracker ${ }^{5}$ at a sampling rate of $1000 \mathrm{~Hz}$. After an initial 9-point calibration- and validation procedure, each participant saw eight practice items. Experimental trials started after a further calibration.

The stimuli were presented according to a Latin Square design. Each of the four resulting lists contained one condition of each of the 40 experimental items interspersed with 90 filler items. The lists were randomized for each participant such that the items were not always shown in the same order. This was done to avoid that some items were always seen at the end of an experimental session when participants are fatigued. All sentences were displayed using a monospaced font in one line across the screen.

In each trial that showed a memory load, participants were presented with three memory nouns for a total of three seconds. Participants were asked to silently read and memorize the words. ${ }^{6}$ Then, the memory nouns disappeared, and an experimental sentence was shown following a drift check. The 'drift check point' was located approximately at the same coordinates as the first letter of the first word in the sentence. Once participants finished reading a sentence, they fixated a small point in the lower right corner of the screen. This fixation triggered the presentation of the next screen. Both the location of the drift check point and the fixation trigger helped avoid random fixations on the sentence that are unrelated to reading. Finally, participants answered a question and were asked to recall the three memory nouns in the correct order, typing the answers.

The experiment had three hard-coded breaks to minimize fatigue, and to ensure relatively homogeneous study conditions for all participants. Re-calibrations were performed after each break, and whenever necessary. The differences in technical specifications for the English,

\footnotetext{
${ }^{5}$ https://www.sr-research.com/products/eyelink-1000-plus/

${ }^{6}$ In Van Dyke and McElree (2006), participants also saw the memory nouns at the beginning of a trial for three seconds but participants were requested to read them aloud. For our study, this change was necessary as the participants' head was placed in a headrest. Reading aloud would have required re-calibrations on most trials due to head movement.
} 
German and Russian study can be found in the supplementary materials.

\section{Predictions}

For all three languages, an interference effect was predicted to occur at the outer RC verb (e.g., fixed/sailed in Table 3). This verb is the critical region in our experiment. Our primary analysis concerned the Load $\times$ Interference interaction, i.e., a reading time slowdown for interfering vs. non-interfering sentences within Load conditions, but not within No load conditions.

Predictions for complex vs. simple version. In the simple versions, it was expected that the Load $\times$ Interference interaction would be of a smaller magnitude than in the complex versions. An alternative hypothesis was that the effect may even disappear altogether when shallow processing is induced.

Predictions for the cross-linguistic comparison between German and Russian vs. English. In German and Russian, the Load $\times$ Interference interaction was expected to be smaller than in English. The reason for this is the richer morphological marking in German and Russian that may lead to better distinguishability of items in memory. If case can be used as an additional cue in German and Russian but not in English, this is expected to reduce interference from the sentence external distractor nouns in German and Russian.

\section{Statistical analyses}

We conducted our analyses within a Bayesian framework (Gelman et al., 2014). In the Bayesian setting, marginal posterior distributions can be computed which provide information about the plausible values of the parameters of interest. One assumption is that every parameter has a prior distribution of plausible values. The posterior can then be computed from the prior and a likelihood function, using Bayes' theorem (posterior $\propto$ prior $\times$ likelihood). In most cases - and this is true for the models we fit here - the posterior distribution cannot be derived analytically, but it can be approximated using Markov Chain Monte Carlo (MCMC) sampling (Gelman et al., 2014). 
We fit Bayesian linear mixed-effects models, using the probabilistic programming language Stan (Carpenter et al., 2016). Memory load, Interference and their interaction were included in the models as fixed effects. The models had full variance-covariance matrices for subjects and for items random effects. In order to interpret the nested effects, we added centered word length as a predictor. This is because the manipulation of the critical verb region resulted in varying word lengths. The contrast coding for the comparisons of our statistical models is specified in Table 5. A log-normal likelihood was assumed for the reading times.

We used regularizing, weakly informative priors for the parameters in our models (Gelman et al., 2017). The prior distribution for the intercept was set at $\operatorname{Normal}(0,10)$. All other parameters were defined as a standard $\operatorname{Normal}(0,1)$ which, for the subjects and items random effects standard deviations, were truncated at 0 . A so-called regularizing LKJ prior distribution was used for the correlation matrix associated with the variance-covariance matrix of the random effects (Lewandowski et al., 2009). Setting its shape parameter $\nu$ (nu) to 2.0 downweights extreme values; this is illustrated in Figure 4 . A $\nu$ parameter value $>1$ will favor less correlation between intercepts and slopes, which seems reasonable given that we do not have any information about the correlations. For each of the statistical models, we ran four chains, each with 4000 iterations. The first half of these samples were discarded as warm-up, or burn-in, samples. The $\hat{R}$-diagnostic (Gelman et al., 2014) as well as visual inspection of trace plots provided us with information about model convergence.

We report the $95 \%$ Bayesian credible intervals $(\mathrm{CrI})$ of the posterior distributions. These tell us the range within which the true parameter lies with a $95 \%$ probability, given the data and model. For easier interpretation the values were back-transformed from the log scale to the millisecond scale. For the fixed effects in the model (i.e., $\log (r t)=\beta_{0}+$ $\beta_{1}$ Load $+\beta_{2}$ Interference $+\beta_{3}$ Interaction) with contrast coding \pm .5 , the posterior of the difference in factor level means on the log scale was back-transformed in the following way: $\exp \left(\beta_{0}+.5 \times \beta_{1}\right)-\exp \left(\beta_{0}-.5 \times \beta_{1}\right)($ Nicenboim et al., 2021) 


\section{LKJ prior}

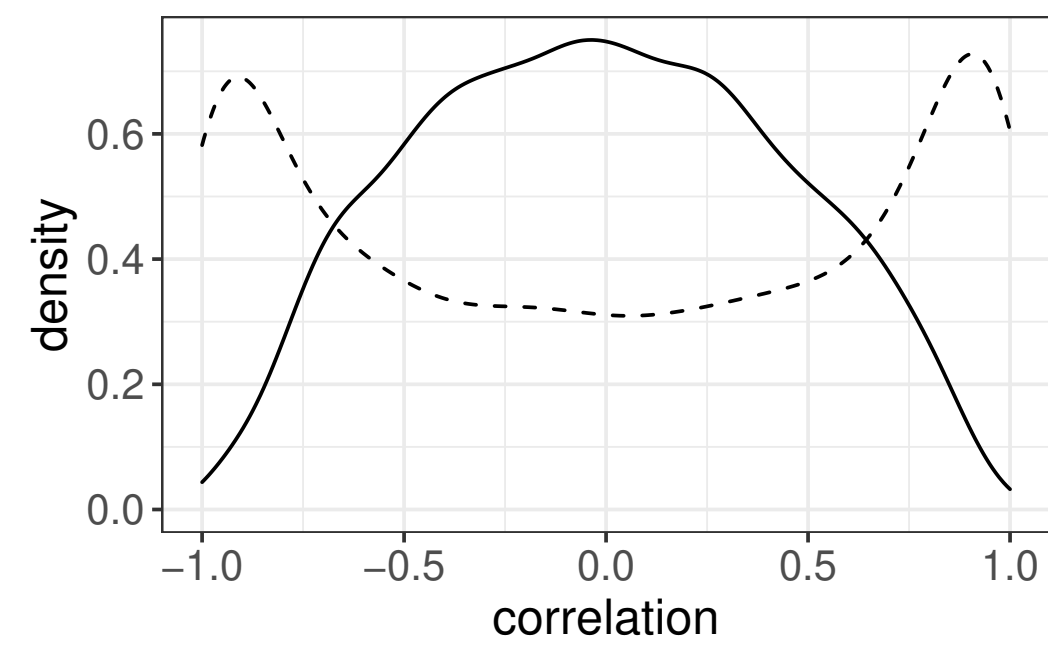

\section{shape parameter}

$v=0.5$

$v=2$

Figure 4. The dashed line shows that when the $\nu$ parameter of Stan's LKJ function is 0.5, less extreme correlation values are downweighted. The solid line shows that changing the $\nu$ parameter value to 2.0 downweights more extreme values.

Condition

Load Interference Interaction

$\begin{array}{llll}\text { a. Load, No interference } & +0.5 & -0.5 & -0.5 \\ \text { b. Load, Interference } & +0.5 & +0.5 & +0.5 \\ \text { c. No load, No interference } & -0.5 & -0.5 & +0.5 \\ \text { d. No load, Interference } & -0.5 & +0.5 & -0.5\end{array}$

Table 5

Contrast coding for effects of Load, Interference and their interaction.

Bayes factor analyses for model comparison. We conducted Bayes factor analyses to evaluate the evidence in favor of one model over another model (Gelman et al., 2014; Jeffreys, 1961; Kass \& Raftery, 1995; Lee \& Wagenmakers, 2014; Schad et al., 2021). Here, Model 0 represents the null hypothesis which assumes the predicted interaction to be zero (the model does not include the interaction term). Model 1 represents the hypothesis that the interaction is not zero (the model includes the interaction term). The Bayes factor (BF) is a ratio of the marginal likelihood of our data given one model over the marginal likelihood of the data 
given the other model:

$$
B F=\frac{P\left(\text { Data } \text { Model }_{0}\right)}{P\left(\text { Data } \text { Model }_{1}\right)}
$$

The Bayes factor can tell us which of the two models is more likely to have generated the data. We thus have a way to quantify the support in favor of one model over another. Jeffreys (1961) as cited in Lee and Wagenmakers (2014) gives a guideline for the interpretation of the Bayes factor (Table 6, minimally adapted from Lee and Wagenmakers, 2014, p. 105).

\begin{tabular}{ll} 
Bayes factor $\left(B F_{01}\right)$ & Interpretation \\
\hline$>100$ & Extreme evidence for M0 \\
$30-100$ & Very strong evidence for M0 \\
$10-30$ & Strong evidence for M0 \\
$3-10$ & Moderate evidence for M0 \\
$1-3$ & Anecdotal evidence for M0 \\
1 & No evidence \\
$1 / 3-1$ & Anecdotal evidence for M1 \\
$1 / 10-1 / 3$ & Moderate evidence for M1 \\
$1 / 30-1 / 10$ & Strong evidence for M1 \\
$1 / 100-1 / 30$ & Very strong evidence for M1 \\
$>1 / 100$ & Extreme evidence for M1 \\
& \\
\hline
\end{tabular}

Table 6

Guideline for the interpretation of the Bayes factor according to Jeffreys (1961) as cited in Lee 85 Wagenmakers (2014). The order of 0 and 1 in BF01 indicates that we look at support in favor of Model 0 over Model 1. BF10 indicates evidence for Model 1 over Model 0.

The Bayes factor is sensitive to the prior distribution (Gelman et al., 2017; Sinharay \& Stern, 2002). Mildly informative priors such as $\mathcal{N}(0,1)$ very likely bias the Bayes factor in support of a model that reflects the hypothesis that the parameter of interest is zero (Mulder \& Wagenmakers, 2016; Rouder et al., 2018). We therefore computed the Bayes factor for more informative priors on the interaction term in Model $1, \mathcal{N}(0,0.1)$ and $\mathcal{N}(0,0.05)$ (see also Nicenboim et al., 2020).

The models were fit using the $\mathrm{R}$ package brms, an interface using Stan to fit Bayesian 
hierarchical models (Bürkner, 2017). For each model, we ran four chains with 10000-30000 iterations each. The first 2000 samples were discarded as warm-up samples. Marginal likelihoods and Bayes factors were computed using the bridge_sampler and bf functions from the bridgesampling R package (Gronau, Sarafoglou, et al., 2017; Gronau, Singmann, et al., 2017).

\section{Results}

Memory recall. Figure 5 shows the recall accuracy of the memory items for non-interfering vs. interfering Load conditions for each experiment version next to the Van Dyke and McElree (2006) recall accuracies. The accuracies in Figure 5A are based on a strict criterion where recall was judged as 'correct' only when all three memory nouns were recalled in the correct order. ${ }^{7}$ Compared to Van Dyke and McElree (2006), our recall accuracies are low, particularly in English when complex comprehension questions were asked. To check that participants did not largely disregard this task, we inspected a more lenient criterion: recall accuracy was judged as 'correct' when either two or three memory nouns were recalled in any order. These results are presented in Figure 5B. The lower recall accuracy in our study may be the result of the participants silently rehearsing the nouns in the memorization task. In Van Dyke and McElree (2006), participants read the memory nouns aloud, possibly facilitating recall (MacLeod et al., 2010; Quinlan \& Taylor, 2013). Another hypothesis is that our participants paid less attention to the recall task than the reading task (see Discussion).

Comprehension question accuracy. The by-condition question response accuracies for all six experiment versions are shown in Figure 6. Filler item accuracies were also high (mean accuracies and standard errors (SE) in English (complex): 91\% (SE .5), English (simple): $93 \%$ (SE 1), German (complex): 88\% (SE .5), German (simple): 97\% (SE .2), Russian (complex): 87\% (SE .5), Russian (simple): 86\% (SE .5).

\footnotetext{
7 A more lenient criterion in Van Dyke and McElree (2006), i.e., recall of three words in any order, had a highly similar accuracy to the strict criterion (non-interfering 80\%, interfering $78 \%$ (SE 2). Removing the strict order criterion also did not change the results for our data (see supplementary materials).)
} 

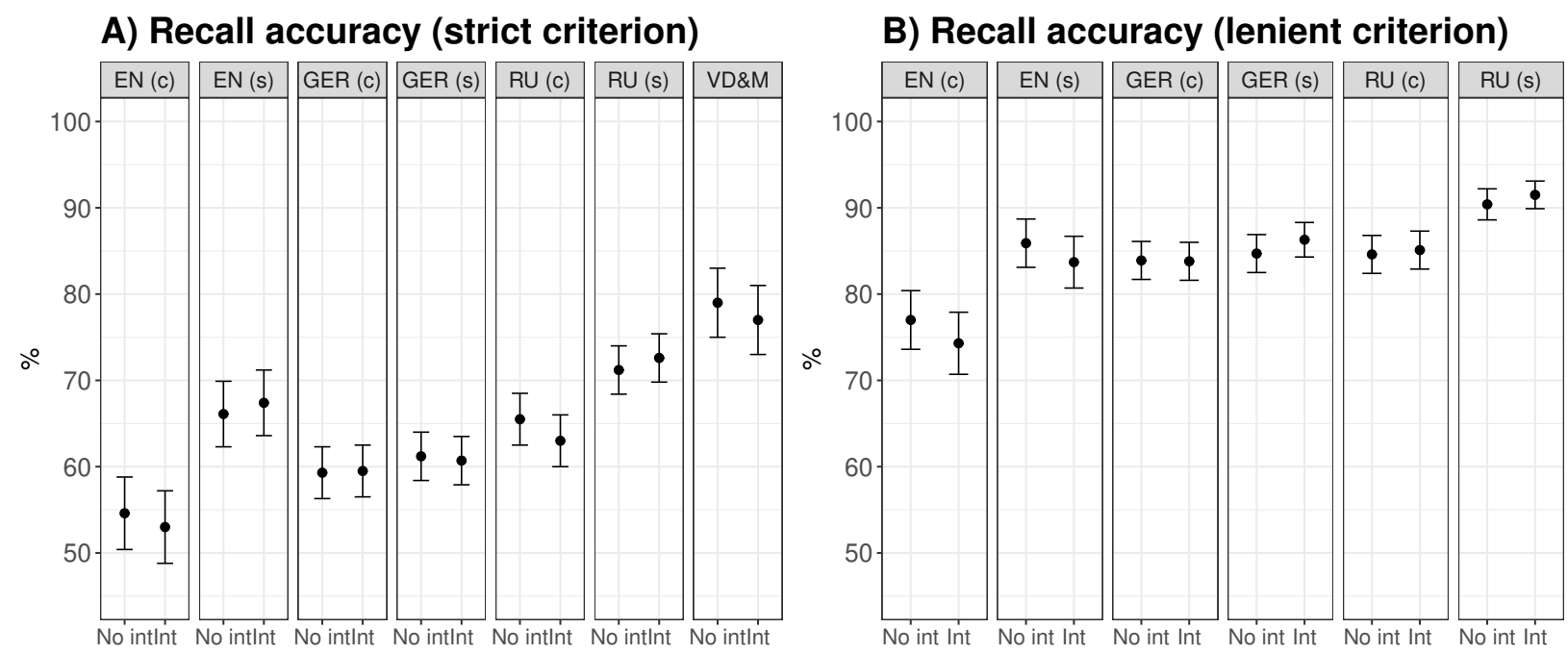

Figure 5. Mean recall accuracies (in percent) with $95 \%$ confidence intervals, A) for a strict criterion (all three words recalled in the correct order), and B) for a lenient criterion (two or three words recalled in any order). EN = English, GER = German, RU = Russian; (c) = complex version, $(\mathrm{s})=$ simple version; VD\&M = Van Dyke \& McElree (2006); No int = No interference condition, Int $=$ Interference condition.

Comprehension question accuracy
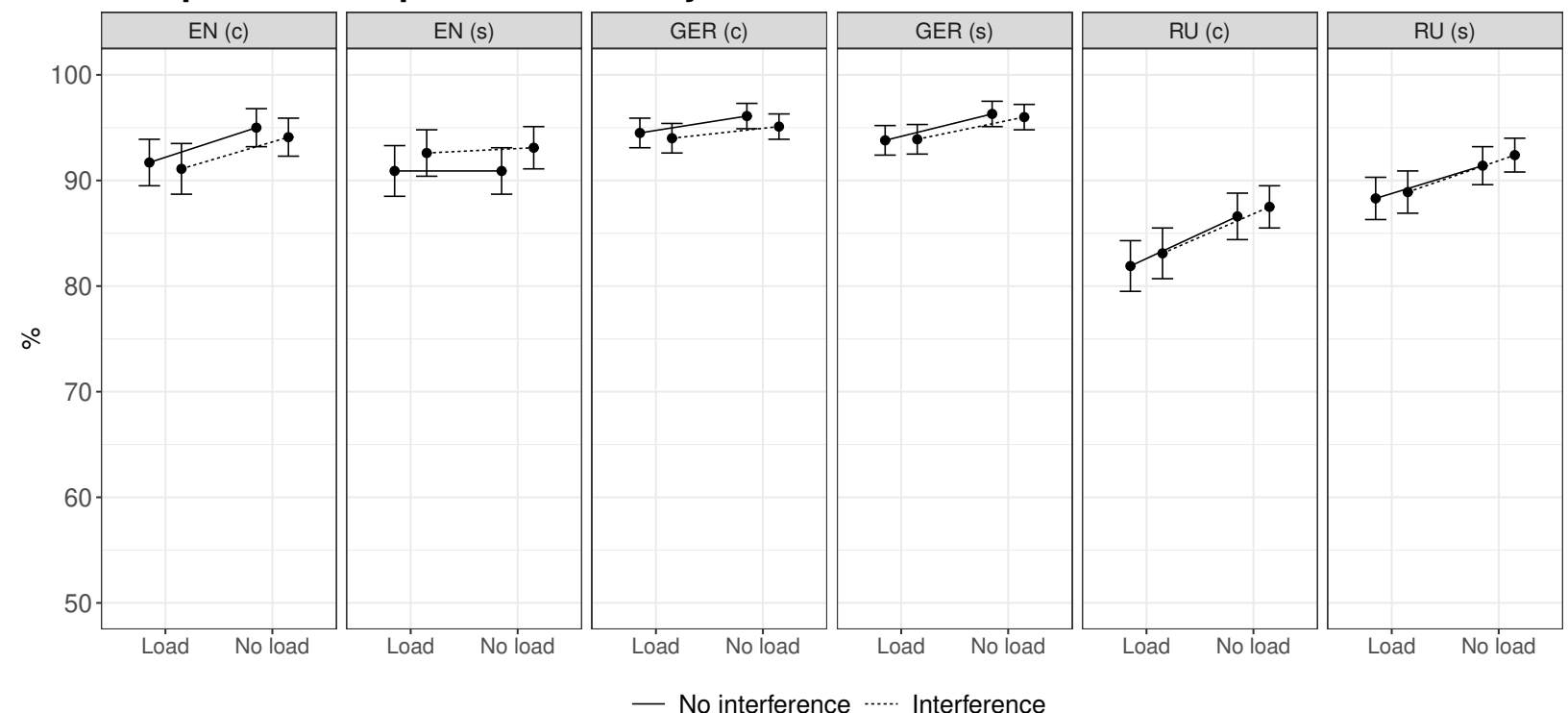

Figure 6. By-condition mean comprehension question accuracies (in percent) with $95 \%$ confidence intervals. EN = English, GER = German, RU = Russian; $(\mathrm{c})=$ complex version, $(\mathrm{s})=$ simple version. 
Reading times. We report the results at the critical verb for the reading measures firstpass reading times (FPRT) and total fixation time (TFT). ${ }^{8}$ FPRT, also referred to as gaze duration, is the sum of all fixations on a word $n$ before any other word is fixated. TFT includes all fixations on a word $n$ (Logačev \& Vasishth, 2013; Rayner, 1998). The raw by-condition means with $95 \%$ confidence intervals for both measures can be inspected in Figure B2.

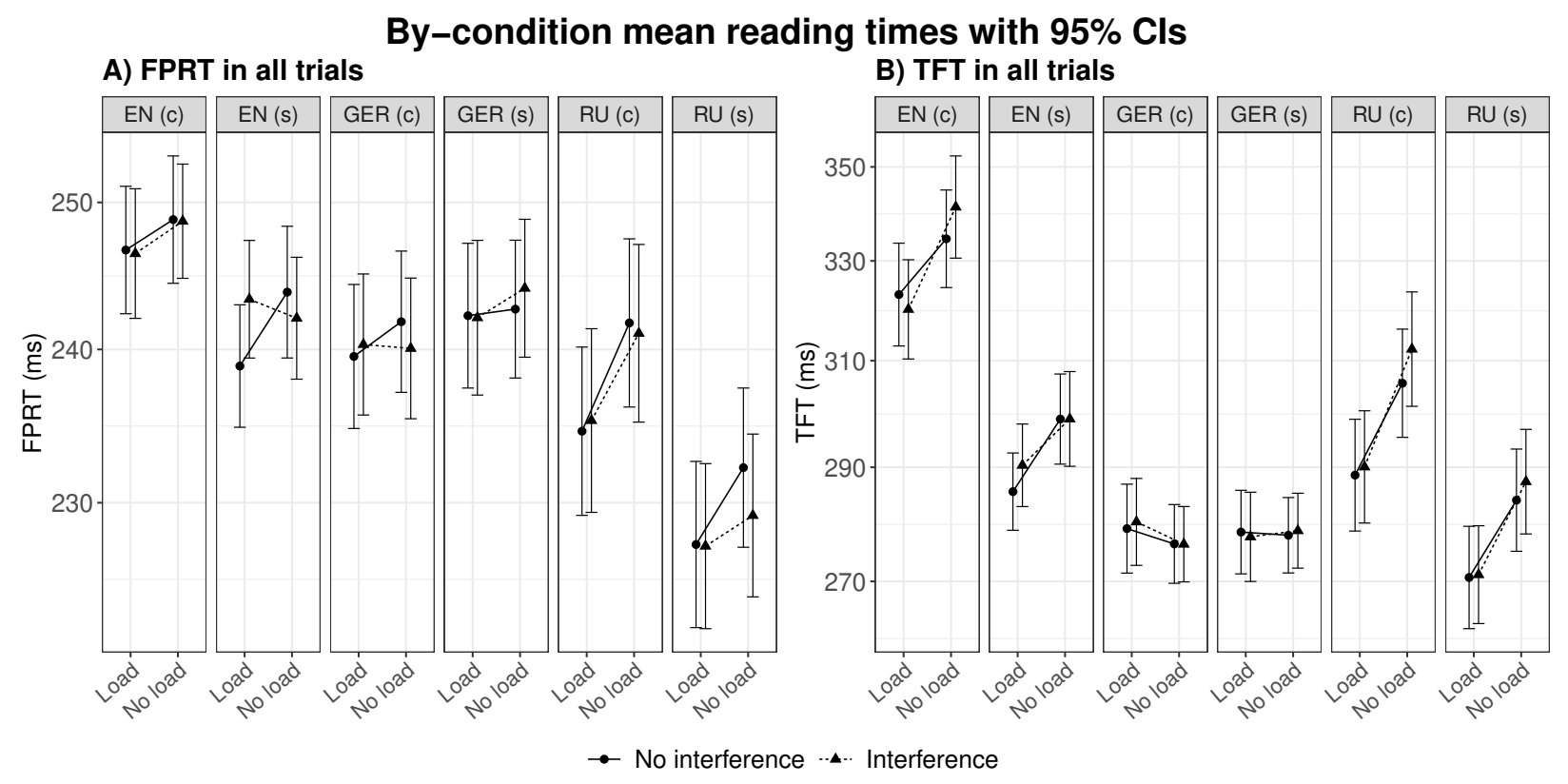

Figure 7. By-condition mean reading times with $95 \%$ confidence intervals. (A) shows first pass reading times (FPRT); (B) shows total reading times (TFT). EN = English, GER = German, RU = Russian; (c) = complex version, (s) = simple version.

Figure 8 shows the results of the Bayesian analysis for English, German and Russian, each in the complex version (left panel) and the simple version (right panel). For the effects of Load, Interference and their interaction, we show the FPRT and TFT means of the posterior distributions with their $95 \%$ credible intervals.

The analysis indicated that reading is overall faster when items have to be memorized, i.e., Load conditions were read faster than No load conditions. Meanwhile, there is no indication

\footnotetext{
${ }^{8}$ We conducted further statistical tests of other commonly analyzed eye-tracking measures, regression-path duration and proportion of first-pass regressions. These are also not reported here as they do not change the conclusions of this paper. All exploratory analyses can be inspected in the supplementary materials (https://osf.io/qremv).
} 
of an overall effect of Interference. This was expected because in this experiment design, once memory load is removed, any potential interference from the memory items is also removed. Therefore, the effect of Interference only tests whether there is a difference between the verbs in conditions a, c vs. b, d.

Effect estimates of the Load $\times$ Interference interaction. The effect of interest is the Load $\times$ Interference interaction. This interaction was expected to have a positive sign. Across all experiments, only the simple versions of English and Russian, in first-pass reading times, show some indication of an interaction in the expected direction. In English (simple, FPRT), the $95 \%$ CrI is $[0,18]$ ms. Nested comparisons show that within Load conditions, there is a reading time slowdown for interfering compared to non-interfering sentences $(95 \%$ CrI $[-1,27] \mathrm{ms})$. In No load conditions, the 95\% CrI is centered around zero ([-19, 9] ms). In Russian (simple, FPRT), the interaction points in the expected direction (95\% CrI [-3, 13] ms). In Figure 9, our FPRT interaction estimates from each experiment are presented next to the Van Dyke and McElree (2006) interaction. Both English and Russian show effect estimates that overlap with the interaction in Van Dyke and McElree (2006).

In contrast to English and Russian, the simple version of German shows a pattern that is inconsistent with the expected Load $\times$ Interference interaction (FPRT: 95\% CrI [-11, 1] ms, nested Load: $[-15,12] \mathrm{ms}$, nested No load: $[-4,21] \mathrm{ms})$. For TFT, the $95 \% \mathrm{CrI}$ is [-16, 0] $\mathrm{ms}$ (nested Load: [-24, 9] ms, nested No load: [-10, 29] ms). Similarly, Russian (complex) also shows a negative sign for the interaction (FPRT: 95\% CrI [-17, -1] ms; nested Load: [-29, 0] ms, nested No load: [-10, 18] ms; TFT: 95\% CrI [-27, 1] ms; nested Load: [-20, 29] ms, nested No Load: [0 to 63] ms). For all other experiment versions, the Load $\times$ Interference interaction is centered around zero.

Before we turn to the Bayes factor results, note that we preregistered the Load $\times$ Interference prediction for TFT, predefining a 'region of practical equivalence' (or 'null region') to interpret the TFT results (e.g., Freedman et al., 1984; Hobbs \& Carlin, 2008; Kruschke, 2015; Spiegelhalter et al., 1994). Because this null region is not suitable for FPRT, for clarity and 
brevity, we use Bayes factors to interpret the results of both reading measures here. The preregistration and the preregistered analysis alongside the code are publicly available in the supplementary materials (https://osf.io/qrcmv).

Bayes factor results for the Load $\times$ Interference interaction. The Bayes factor results can tell us whether there is evidence in favor of or against the Load $\times$ Interference interaction. Figure 10 shows the Bayes factor results $\left(B F_{01}\right)$ for Model 0 (not including interaction term) over Model 1 (including interaction term), separately for the complex and simple versions in each language. Panel (a) visualizes results for first-pass reading times, and (b) for total reading times. The Bayes factor values (y-axis) were computed for increasingly uninformative prior distribution standard deviations (SD) on the interaction (x-axis).

Most notably, the Bayes factor for English (simple, FPRT) shows some very modest evidence for the interaction in the predicted direction, at least under the more informative $\mathcal{N}(0,0.05)$ prior. For German (simple, TFT) and Russian (complex, FPRT, TFT), the Bayes factors very weakly support an unexpected interaction under the more informative prior. For all other experiment versions the Bayes factors suggest that the data are more likely to have been generated by Model 0, showing anecdotal to moderate evidence against a Load $\times$ Interference interaction.

Effect estimates of the Language $\times$ Load $\times$ Interference interaction. We further tested whether the Load $\times$ Interference interaction is modulated by language. The three-way Language $\times$ Load $\times$ Interference interaction indicates that processing in English differs from German and Russian (Figure 11).

In addition to the Language manipulation, we manipulated depth of processing. This manipulation did not show the expected pattern, namely, a smaller, or no interference effect in the simple compared with the complex experiment versions. In English, the reading time patterns are compatible with the idea that processing differs across the two version. However, unexpectedly, interference is observed only in the simple version (for Processing depth $\times$ Load $\times$ Interference interactions, see supplementary materials). 


\section{English (critical verb)}
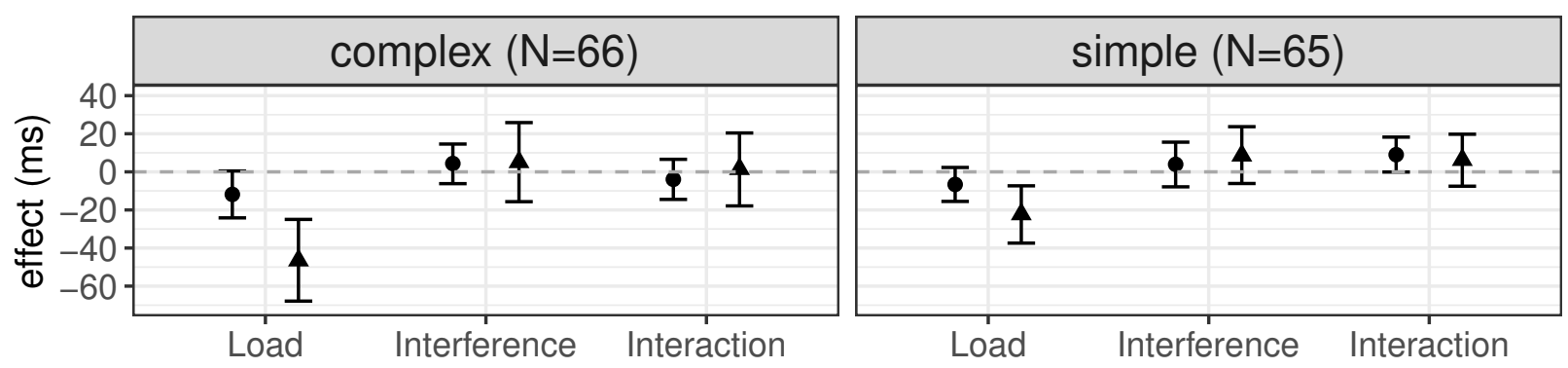

German (critical verb)
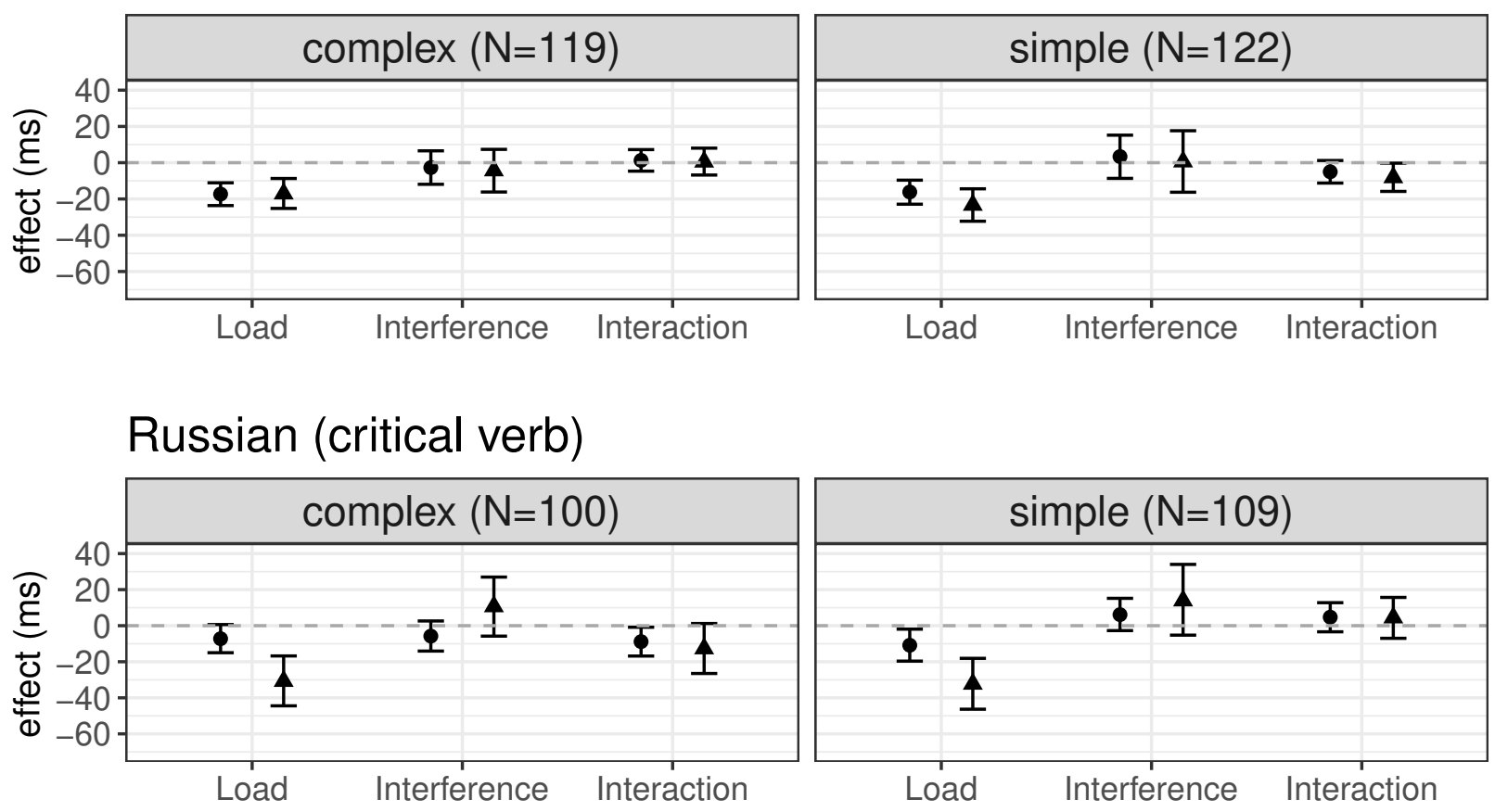

- FPRT $\triangle$ TFT

Figure 8. Effect of Load, Interference and their interaction at the critical relative clause verb for the complex and the simple versions of the English, German, and Russian experiments. Values were back-transformed from the log scale to the millisecond scale. FPRT = first-pass reading times, $\mathrm{TFT}=$ total fixation times. 


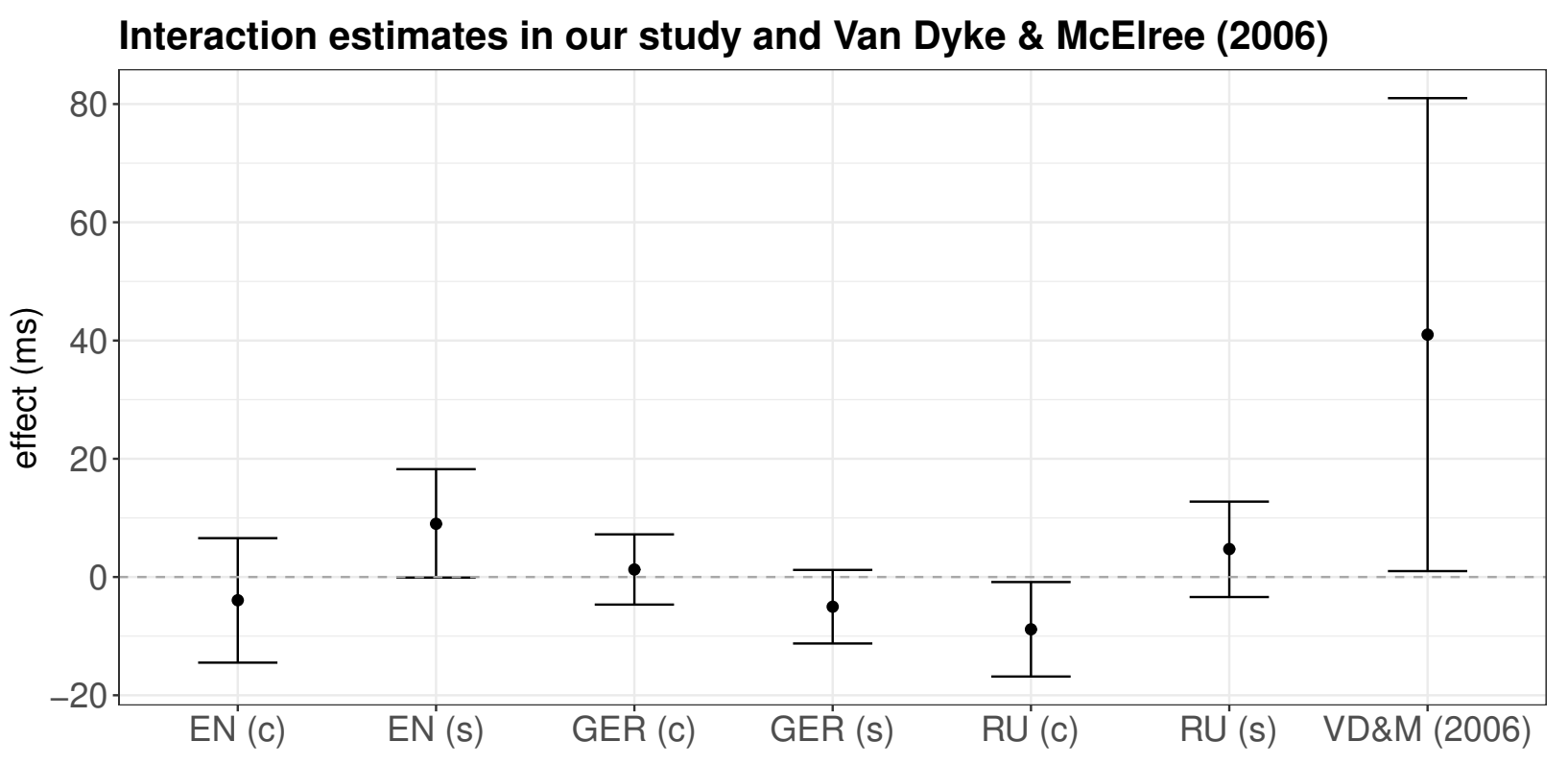

Figure 9. Interaction estimates with $95 \%$ credible intervals from our study (first pass reading times), compared with interaction estimate with $95 \%$ confidence interval from Van Dyke \& McElree (2006) (self-paced reading times). EN = English, GER = German, RU = Russian, (c) = complex version, $(\mathrm{s})=$ simple version.

\section{Discussion}

This study re-investigated proactive cue-based retrieval interference in sentence comprehension. Our large-sample cross-linguistic study only shows anecdotal evidence for the predicted interaction in one language, version and reading measure. At best, we can conclude that the Bayes factors very weakly support the expected interaction in English (simple). However, in German (simple) and Russian (complex), there was some weak support for an interaction that did not have the predicted positive sign. For all other experiment versions, the Bayes factors revealed moderate evidence against the interaction.

Overall, our data do not show much support for cue-based retrieval interference from sentenceexternal distractors. Before drawing conclusions, it is important to rule out task-related explanations for these results. In the dual-task design, the interference effects are entirely contingent on the encoding of the distractor nouns in memory. If the memory nouns are not encoded in memory, then no interference effects would be expected. This is a possibility if 


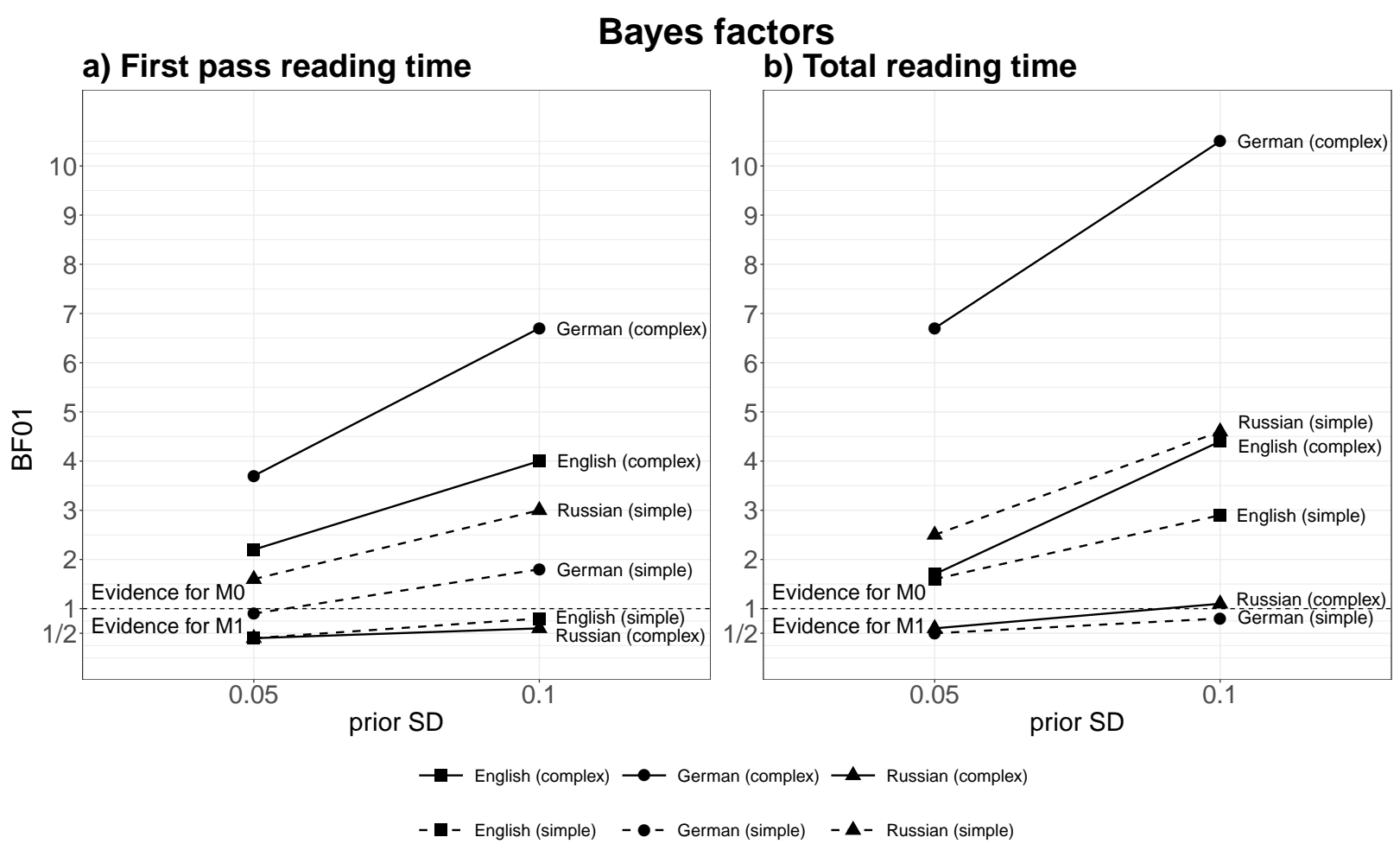

Figure 10. Bayes factor results for Model 0 over Model 1 (BF01) in a) first pass reading time for the complex and the simple versions of the English, German and Russian experiments. Bayes factor values are shown for increasingly uninformative prior distributions: $\mathcal{N}(0,0.05)$, and $\mathcal{N}(0,0.1)$

participants only paid close attention to the reading task but not the recall task. Although they were instructed to attend to both, if participants did not perform both tasks concurrently in our experiments, then the lack of an interaction would not necessarily bear on the theoretical question under investigation. Our study had a low recall accuracy, compared with the previous study by Van Dyke and McElree (2006). The low memory recall accuracy could have contributed to our study not observing clear support for proactive interference effects. If so, can interference effects be observed when all three memory nouns are encoded in memory? We checked this hypothesis by analyzing the English, German and Russian data with perfect recall. The 'high recall' data show similar estimates to our original analysis (see Appendix B). For the simple version of the English experiment, the interaction estimate has a slightly wider credible interval ranging from -5 to $17 \mathrm{~ms}$. These results indicate that even when all memory nouns are encoded in memory, they do not seem to interfere with within-sentence 


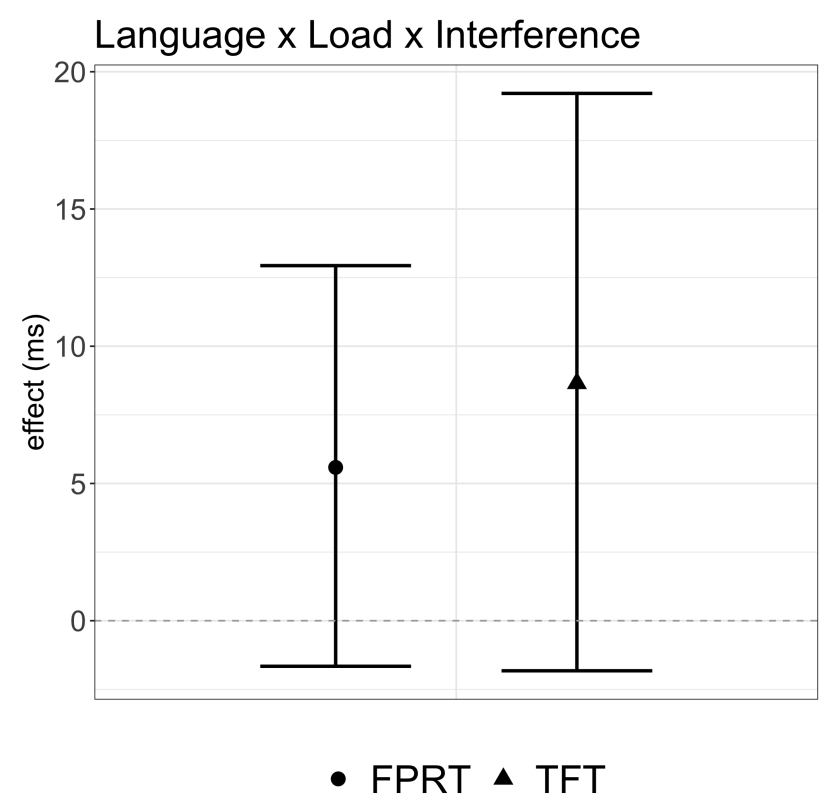

Figure 11. Shown are the posterior means and 95\% credible intervals for the Language $\times$ Load $\times$ Interference interaction (first-pass reading times, total reading times). For the analysis, the combined data from all experiment versions had 304 subjects and 240 items. We tested whether the Load $\times$ Interference interaction in English differs from German and Russian. The contrasts for the factor Language were specified using the $\mathrm{R}$ package hypr (Rabe et al., 2020), testing the null hypothesis H0: EN - (GER + RU) $/ 2=0$, i.e., whether the difference between the Load $\times$ Interference interaction in English $(\mathrm{EN})$ vs. the interaction in German (GER) and Russian (RU) (averaged) is equal to zero. English was coded as +0.66 , and German and Russian as -0.33 .

dependency resolution in any of the other experiment versions.

A related concern is that the dual-task paradigm could also have failed if participants paid attention only to the recall task but not to the reading task. In this case, we also expect to see no interference. However, the high comprehension question accuracies across all experiment versions suggest that participants attended to the reading task. In trials where recall was perfect, comprehension question accuracy is also very high (Appendix B). Moreover, in perfect recall trials, the by-condition reading times are not unusually fast which may have been an indication that the reading task was not attended to (Appendix B). This minimizes the concern that the failure to observe clear proactive interference effects resulted from participants disregarding one of the two tasks in the dual-task paradigm.

Furthermore, our specific stimuli may have contributed to most experiment versions not 
showing the predicted reading time pattern. Our study used filler-gap dependencies with two embedded relative clauses. The expectation was that these sentences may increase our chances to detect an effect compared with the object clefts in Van Dyke and McElree (2006). In the latter, the retrieval target was in linguistic focus, whereas in our sentences, it was not. It was reasoned that items in focus have more distinctive memory representations which may reduce the magnitude of the interference effect. Conversely, it could be argued that a target in linguistic focus, as in the clefted constructions, is less distinguishable from the prominent sentence-external distractors. In Van Dyke and McElree (2006), both the target as well as the memory nouns were given special status, which could make them more confusable. This could be the case if prominence is used as a retrieval cue (e.g., Kush et al., 2019).However, our Russian data speak against the hypothesis that clear interference effects were not observed due to the specific stimuli used here. The Russian stimuli in our study use demonstrative pronouns for the target NP, as there are no articles in Russian. This increases the prominence of the target compared to the default option (use of the NP without a demonstrative pronoun). Despite the special status of the target in Russian, there was no support for the predicted interference effect.

\section{General Discussion}

The main goal of this study was to re-investigate cue-based theories' prediction of cuedependent retrieval interference. The present study is the first to test proactive similaritybased retrieval interference cross-linguistically, using the same method, design, and comparable sentence structures across languages. We aimed to extend previous findings on English object clefts to the online processing of filler-gap dependencies, using the dual-task paradigm by Van Dyke and McElree (2006). In addition, the relatively large sample sizes in German and Russian compared to most previous interference studies provide more precise estimates of the interference effect. A further novel contribution of this study is a within-subjects manipulation of processing depth, investigating proactive interference under varying task 
demands.

Our analyses only showed some weak evidence in favour of the predicted Load $\times$ Interference interaction in the simple version of the English experiment. Thus, only the English data lend any support to the hypothesis that semantically similar, sentence-external distractors in memory can interfere with retrieval during real-time sentence comprehension. In contrast to English, German and Russian did not show evidence for this proactive retrieval interference effect, despite using the same method and design, and comparable sentence structures across languages.

The weak evidence for interference in English and evidence against interference in German and Russian may point to cross-linguistic processing differences. In German and Russian the accusative case marking of the grammatical object may increase distinguishability of the retrieval target, and therefore eliminate interference during online dependency formation. Whether these differences are due to case marking attenuating interference is speculative, and requires further investigation, using a cross-linguistic design that explicitly manipulates case marking.

If proactive interference occurs in English but not in German or Russian, then it is surprising that interference was only observed in English when simple questions were asked but not when complex questions were asked. Our depth of processing hypothesis postulated that inducing shallow processing would lead to less or no interference during online sentence comprehension (Logačev \& Vasishth, 2016; Swets et al., 2008). However, only the simple version showed some support for proactive interference. In the complex version, the effect was not replicated. Here, we refer to replication as observing overlapping effect estimates with the predicted positive sign. What could be the reason for not replicating the effect in the complex conditions, despite testing the same participants across the two experiment versions? One explanation might be that this effect only arises under good-enough processing. Laurinavichyute and von der Malsburg (2021a) recently found support for agreement attraction effects under superficial but not deep processing conditions. Our study might also reveal this difference in 
processing depth. Furthermore, in our study, it is plausible that the difference in processing depth does not reflect superficial vs. deep processing as hypothesized, but rather "typical" vs. deep processing. That is, the simple questions conditions may not have resulted in underspecification of syntactic dependencies, as intended. Rather, in this version, participants may have engaged in "typical", attentive sentence processing. The formal lab setting and the high comprehension question accuracies would speak to this proposal. By comparison, the more complex questions may have induced a more unnatural, heightened attention state for the participants. Under this view, interference may occur in "typical" language processing mode, in which the parser attempts to resolve all dependencies. However, interference does not arise in a deep processing mode when particular attention is required, such as maintaining each dependency in memory to correctly answer a comprehension question. The interaction estimate in the simple version of Russian (vs. the complex version) may also point towards this heightened attention hypothesis, although the Bayes factors in this study offered no evidence for the interference effect in the simple version of Russian.

An alternative explanation for observing an interference effect in English under low but not high task demands is that this result is due to noise in the data. Given that - of all experiment versions - only the lower-sample size English study (simple version, FPRT) showed weak evidence for proactive interference, this could be an accidental outcome that may not be replicable in a future study. To show that proactive retrieval interference is replicable under a low processing load, a confirmatory experiment would have to be conducted (e.g., de Groot, 1956/2014; Nicenboim et al., 2018; Vasishth et al., 2018).

If cue-based parsing mechanisms are an integral part of language processing, it is interesting that our study does not show cross-linguistic support for it. Why don't we observe the predicted reading time pattern, with one exception? While cross-linguistic processing differences and processing depth might play a role, other factors could have contributed to our results. As foreshadowed above, interference in sentence processing is likely to be a subtle phenomenon that is difficult to detect. Recall that the meta-analysis by Jäger et al. 
(2017) on non-agreement subject-verb dependencies showed an interference effect of $13 \mathrm{~ms}$ with a $95 \%$ credible interval ranging from 2 to 28 ms. Similarly, a self-paced reading study on number interference by Nicenboim et al. (2018) with a participant sample size of 182 showed an interference effect of $9 \mathrm{~ms}(95 \% \mathrm{CrI}[0,18] \mathrm{ms})$. Our English experiment obtained a similarly precise, and small, estimate of the effect of interest in first-pass reading times (95\% CrI $[0,18] \mathrm{ms})$. However, with the rather small sample size, we are likely to find ourselves in a relatively low power scenario, as Figure 1 demonstrated. Even with larger participant samples, as in German or Russian, such small effects may remain undetected. Consequently, to detect proactive interference effects would require significantly more resources, or more sensitive methods.

This study may also show little support for proactive interference because proactive interference effects are overall weaker than retroactive interference effects. For example, Van Dyke and McElree (2011) showed in a within-subjects/items design that proactive interference (from within-sentence distractors) is overall weaker than retroactive interference. This finding is supported by a meta-analysis result in Jäger et al. (2017), showing that proactive interference leads to a smaller reading time slowdown than retroactive interference. Proactive interference from sentence-external materials could be even more subtle. Distractors may predominantly play a role when they appear within a sentence, particularly when the distractor intervenes linearly between the retrieval target and retrieval site. For example, the retrieval cues used to reactivate the filler noun phrase may strongly distinguish within-sentence material from other material in working memory. This theoretical possibility has been suggested by authors who proposed that clause-bounding retrieval cues are used to guide retrieval (Wagers et al., 2009). There is also some empirical evidence that is compatible with this idea: Dillon et al. (2017) showed that retrieval interference is diminished when the distractors are inside appositive relative clauses, which may be seen as a parenthetical distinct from the target sentence. These studies suggest that the context of encoding of the distractor-inside a restrictive relative clause, or inside a more syntactically independent appositive relative clause - may modulate 
the degree of retrieval interference observed. If the context of encoding a distractor element is critical, then cue-based retrieval theories might predict only very small, if any, interference from sentence-external distractors of the sort tested here.

In sum, our study provides only weak evidence that proactive retrieval interference from sentence-external material can interfere with within-sentence dependency resolution in English filler-gap dependencies. This is in line with previous research reporting semantic proactive interference in online sentence comprehension (Van Dyke \& McElree, 2006). Our English data further suggest that interference may be contingent on the depth of processing. Surprisingly, the effect occurred under a lower task demand. These data pinpoint the source of difficulty at the retrieval point, when semantic retrieval cues do not uniquely match the retrieval target. This finding is compatible with cue-based retrieval accounts, suggesting that a cue-dependent retrieval mechanism is employed in online dependency resolution. In particular, this retrieval mechanism can use semantic retrieval cues to reactivate items in memory. Two further languages, German and Russian, revealed either equivocal evidence, or evidence against the predicted interference effect, possibly hinting at between-language processing differences that cue-based theories do not currently account for.

The findings from our cross-linguistic large-sample study allow for limited conclusions. In the psychological sciences, an argument has been made for more cautious conclusions, as single studies frequently overstate the generality of effects (Simons et al., 2017; Yarkoni, 2019). We also favor this approach in the reporting of psycholinguistic research results. Overall, this study only modestly consolidates evidence for cue-dependent retrieval interference in the online comprehension of English filler-gap dependencies. Until further data become available, our findings suggest that proactive retrieval interference from sentence-external material arises only in very specific linguistic contexts. 


\section{Conclusions}

Our data suggest that extra-sentential items encoded in memory can, but may not always, interfere with within-sentence dependency formation. Our study did not find cross-linguistic support for proactive interference, suggesting that language-specific features such as distinctive case marking may reduce interference effects. The only weak evidence comes from English sentence comprehension under low task demands. This indicates that under deep processing, interference might be eliminated. Importantly, the proactive interference of the type shown here has its source at retrieval, suggesting that a cue-based mechanism-using semantic cues for retrieval - is at play during real-time dependency formation.

\section{Acknowledgements}

We are grateful to our lab manager Johanna Thieke (University of Potsdam, Germany) and the following research assistants for their help with data collection for the German experiment: Alexandra Lorson, Maria Korochkina, Elna Haffner, Marie de la Fuente, Romy Leue, Luzie Ahrens, Hanna Eversmann, Chiara Tschirner. For the English experiment (UMass Amherst, USA): Austin Tero and for the Russian experiment (Higher School of Economics Moscow, Russia): Maria Ignashina.

This research was funded by the Deutsche Forschungsgemeinschaft (DFG, German Research Foundation) - Projektnummer 317633480 - SFB 1287, Project B03. 


\author{
Appendix A \\ Experimental materials (German \& Russian)
}

\title{
German stimuli
}

We created 40 experimental items for the complex and 40 items for the simple version of the experiment. Table A1 shows two example items, one followed by a complex and one followed by a simple comprehension question. The critical dependency is between the relative clause verb steuerte/reparierte ('steered'/'repaired') and the sentence-initial NP Das Boot ('The boat').

The German stimuli differed from the English materials in the following way: In Figure 3, we showed that for German, the relative pronoun is overtly marked for accusative case whereas in English, the complementizer that is not. This is an important distinction, because in German, case could serve as an additional cue for retrieval and, hence, reduce interference. For half of the items, the sentence-initial target noun phrase is of masculine grammatical gender such that the relative pronoun of the following object relative clause is unambiguously marked for accusative case (Figure 3). Note, however, that for the other half of the items, the target noun phrase is neuter such that the surface form of the relative pronoun is ambiguous between nominative and accusative case, as in the example in Table A1. To increase naturalness of the German sentences, an adverb preceded the critical relative clause verb because a prepositional- or adverbial phrase, as was added in English, is not licensed in the post-verbal position in German.

\section{Russian stimuli}

The Russian study followed the same design as the English and German study. The complex and simple version each had 40 items. Table A2 shows two example items. The critical dependency is between the relative clause verb сломала/присмотрела ('broke'/'found') and the sentence-initial NP Tо кресло (The armchair).

Differences between Russian vs. English and German are the following: An adverb was 
Table A1

German example items (complex and simple version).
A) Memory load:
Kühlschrank
Waschmaschine
Computer
fridge
washing machine
computer

\section{No interference}

Das Boot, das der Mann, der am Meer lebte, gestern steuerte, schien schon alt zu sein. The boat, that the man, who at sea lived, yesterday steered, seemed already old to be.

\section{Interference}

Das Boot, das der Mann, der am Meer lebte, gestern reparierte, schien schon alt zu sein. The boat, that the man, who at sea lived, yesterday repaired, seemed already old to be.

\section{No memory load:}

\section{No interference}

Das Boot, das der Mann, der am Meer lebte, gestern steuerte, schien schon alt zu sein. The boat, that the man, who at sea lived, yesterday steered, seemed already old to be.

\section{Interference}

Das Boot, das der Mann, der am Meer lebte, gestern $\underline{\text { reparierte, }}$, schien schon alt zu sein. The boat, that the man, who at sea lived, yesterday repaired, seemed already old to be.

'The boat that the man who lived by the sea steered/repaired seemed to be quite old.'

'Complex' question: 'Hat der Mann am Meer gelebt?' (Did the man live by the sea'?)

$\begin{array}{llll}\text { B) Memory load: } & \text { Parfüm } & \text { Rauch } & \text { Leder } \\ & \text { perfume } & \text { smoke } & \text { leather }\end{array}$

\section{No interference}

Der Kaffee, den der Genießer, der in der Rösterei saß, gerne trank, schien äußerst aromatisch zu sein. The coffee, that the connoisseur, who in the roastery sat, gladly drank, seemed most aromatic to be.

\section{Interference}

Der Kaffee, den der Genießer, der in der Rösterei saß, gerne roch, schien äußerst aromatisch zu sein. The coffee, that the connoisseur, who in the roastery sat, gladly smelled, seemed most aromatic to be.

\section{No memory load:}

\section{No interference}

Der Kaffee, den der Genießer, der in der Rösterei saß, gerne trank, schien äußerst aromatisch zu sein. The coffee, that the connoisseur, who in the roastery sat, gladly drank, seemed most aromatic to be.

\section{Interference}

Der Kaffee, den der Genießer, der in der Rösterei saß, gerne roch, schien äußerst aromatisch zu sein. The coffee, that the connoisseur, who in the roastery sat, gladly smelled, seemed most aromatic to be.

'The coffee that the connoisseur who sat in the roastery drank/smelled seemed to be most aromatic.' 'Simple' question: 'Wurde in diesem Satz eine Rösterei erwähnt?' (Was a roastery mentioned in this sentence?) 
Table A2

Russian example items (complex and simple version).

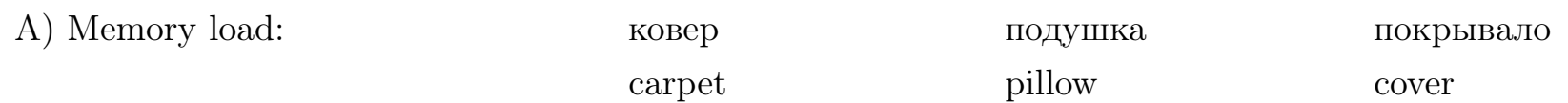

No interference

То кресло, которое старушка, любящая антиквариат сломала

недавно, относится к . . .

The armchair, that elderly woman, loving antiques broke recently, belongs to ...

Interference

То кресло, которое старушка, любящая антиквариат п्исмотрела недавно, относится к ... The armchair, that elderly woman, loving antiques found recently, belongs to ...

No memory load:

No interference

То кресло, которое старушка, любящая антиквариат сломала недавно, относится к ... The armchair, that elderly woman, loving antiques broke recently, belongs to ... Interference

То кресло, которое старушка, любящая антиквариат присмотрела недавно, относится к ... The armchair, that elderly woman, loving antiques found recently, belongs to ...

'The armchair that the elderly woman who loves antiques recently broke/found belongs to the Chippendale style.' Complex question: Did the elderly woman love antiques?

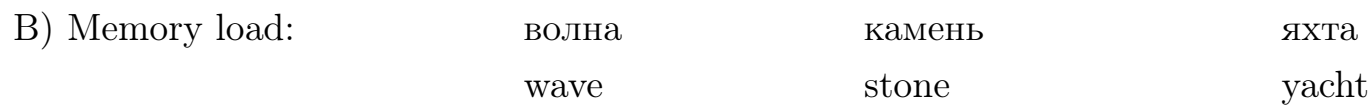

No interference

Тот матрас, который акула, плавающая в море, прокусила неожиданно для туриста, принадлежит... The mattress, that shark, swimming in sea bit through surprisingly for tourist belongs to...

Interference

Тот матрас, который акула, плавающая в море, заметила неожиданно для туриста, принадлежит... The mattress, that shark, swimming in sea spotted surprisingly for tourist belongs to...

No memory load:

No load, No interference

Тот матрас, который акула, плавающая в море, прокусила неожиданно для туриста, принадлежит... The mattress, that shark, swimming in sea bit through surprisingly for tourist belongs to...

No load, Interference

Тот матрас, который акула, плавающая в море, заметила неожиданно для туриста, принадлежит... The mattress, that shark, swimming in sea spotted surprisingly for tourist belongs to...

'The inflatable mattress that the shark swimming in the sea surprisingly spotted/bit through, belonged to the tourist's daughter.

Simple question: Was an ophthalmologist mentioned in the sentence? 
added after the critical relative clause verb for greater naturalness of the sentence. As there are no articles in Russian, the demonstrative pronouns тот (masculine), та (feminine) and To (neuter) (that) were used for the sentence-initial NP. The demonstratives make the NP more prominent compared to the default option of the NP without a demonstrative pronoun, and in comparison with our English and German study. This is similar to the Van Dyke and McElree (2006) study which used object cleft sentences that increase the prominence of the target NP. Case marking on the relative pronouns is overt in Russian, although for masculine and neuter the surface form is case ambiguous. One third of items had a feminine, one third a masculine, and another third a neuter target NP.

\section{Filler items}

English. For the English study, 50 "true" filler items of two varying syntactic structures were created for each of the two experiment versions. 25 were object cleft constructions and 25 were short, simple sentences starting with a quantifier. A further 40 filler items came from another experiment that tested the processing of object- vs. subject relative clauses. All filler items were followed by a comprehension question, and half of all fillers were preceded by three memory nouns.

German. 90 filler items were created for each of the two versions. 30 sentences were object cleft-sentences with two embedded relative clauses (the outer relative clause being an object relative clause, the most embedded relative clause being a subject relative clause). Here half of the questions targeted the object-verb dependency between the sentence-initial noun phrase and the object relative clause verb. A further 30 were subordinate clause-main clause constructions starting with the subordinate conjunction that, and the remaining 30 filler sentences were subject-extracted RC structures.

Russian. For each of the two versions, 90 filler items of varying syntactic structures were created. 30 sentences were object cleft-sentences with an embedded relative clause. A further 30 were subordinate clause-main clause constructions starting with a subordinate 
conjunction expressing causal relationships, and the remaining 30 filler sentences were sentences of various structures randomly selected from the Russian National Corpus (http: //www.ruscorpora.ru/). 


\section{Appendix B}

Perfect recall data

\section{Comprehension question accuracy in perfect recall trials}

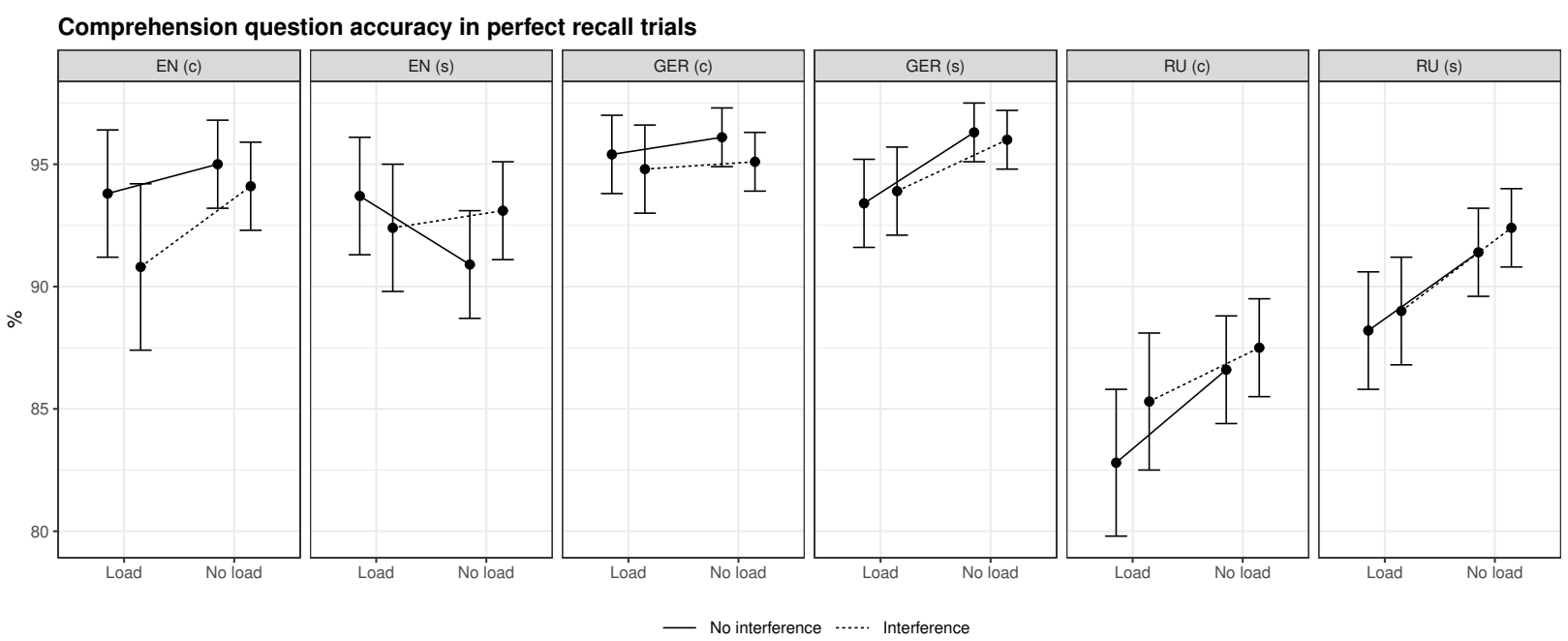

Figure B1. By-condition mean comprehension question accuracies (in percent) with $95 \%$ confidence intervals in perfect recall trials. EN = English, GER = German, RU = Russian; (c) = complex version, $(\mathrm{s})=$ simple version 
Raw by-condition reading times in perfect recall data

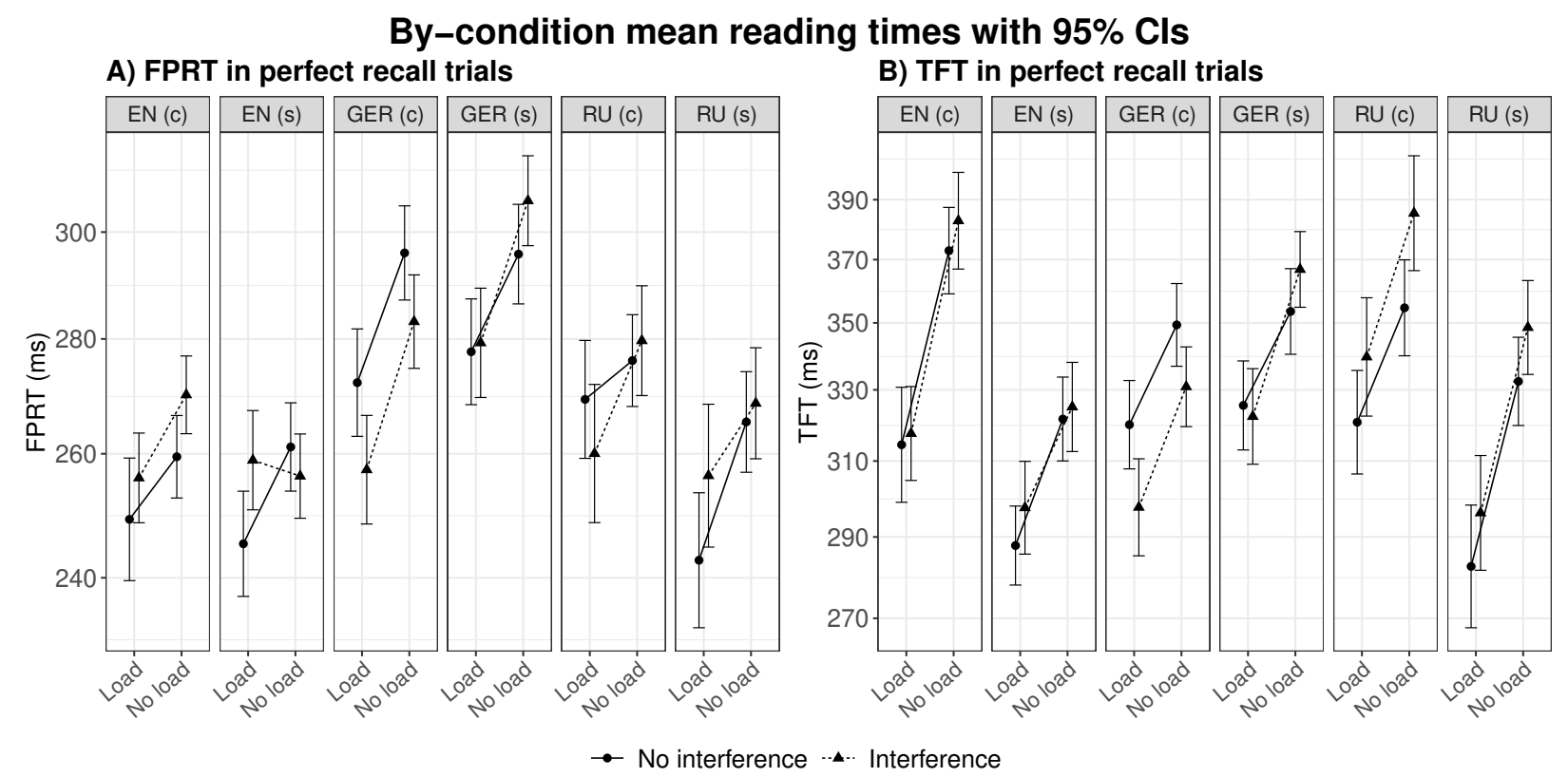

Figure B2. By-condition mean reading times with $95 \%$ confidence intervals. In (A) and (B), FPRT and TFT are shown for trials with perfect recall, i.e., recall of three memory nouns in the correct order. EN = English, GER = German, RU = Russian; $(\mathrm{c})=$ complex version, $(\mathrm{s})$ $=$ simple version. 
Reading time analyses for data with perfect recall

\begin{tabular}{llcc}
\hline Study & Load & Interference & Interaction \\
& TFT Posterior mean [95\% credible intervals] \\
\hline English, complex & $-54 \mathrm{~ms}[-77,-30]$ & $7 \mathrm{~ms}[-18,32]$ & $4 \mathrm{~ms}[-19,27]$ \\
English, simple & $-27 \mathrm{~ms}[-45,-9]$ & $3 \mathrm{~ms}[-13,19]$ & $0 \mathrm{~ms}[-17,17]$ \\
\cline { 2 - 4 } German, complex & $-21 \mathrm{~ms}[-30,-11]$ & $-4 \mathrm{~ms}[-16,7]$ & $0 \mathrm{~ms}[-9,9]$ \\
German, simple & $-26 \mathrm{~ms}[-38,-15]$ & $6 \mathrm{~ms}[-13,25]$ & $-5 \mathrm{~ms}[-14,4]$ \\
\cline { 2 - 4 } & $-34 \mathrm{~ms}[-49,-18]$ & $15 \mathrm{~ms}[-2,32]$ & $-9 \mathrm{~ms}[-25,8]$ \\
Russian, complex & $-42 \mathrm{~ms}[-56,-28]$ & $9 \mathrm{~ms}[-10,28]$ & $0 \mathrm{~ms}[-12,12]$ \\
\hline
\end{tabular}

Table B1

Total fixation times results for the subset of the data with three recalled memory nouns: Effect of Load, Interference and their interaction for both the complex and the simple version of the English, German and Russian experiment. 


\begin{tabular}{llcc}
\hline Study & Load & Interference & Interaction \\
& FPRT Posterior & mean $[\mathbf{9 5 \%}$ credible intervals $]$ \\
\hline English, complex & $-12 \mathrm{~ms}[-27,3]$ & $4 \mathrm{~ms}[-9,16]$ & $-4 \mathrm{~ms}[-17,7]$ \\
English, simple & $-9 \mathrm{~ms}[-20,2]$ & $3 \mathrm{~ms}[-8,15]$ & $8 \mathrm{~ms}[-3,20]$ \\
\cline { 2 - 4 } German, complex & $-18 \mathrm{~ms}[-26,-11]$ & $-4 \mathrm{~ms}[-13,5]$ & $1 \mathrm{~ms}[-7,8]$ \\
German, simple & $-17 \mathrm{~ms}[-25,-9]$ & $8 \mathrm{~ms}[-5,21]$ & $-2 \mathrm{~ms}[-9,6]$ \\
\cline { 2 - 4 } Russian, complex & $-8 \mathrm{~ms}[-17,2]$ & $-3 \mathrm{~ms}[-12,6]$ & $-6 \mathrm{~ms}[-15,3]$ \\
Russian, simple & $-15 \mathrm{~ms}[-25,-5]$ & $7 \mathrm{~ms}[-2,17]$ & $6 \mathrm{~ms}[-3,15]$ \\
\hline
\end{tabular}

Table B2

-First-pass reading times results for high recall accuracy: Effects of Load, Interference and their interaction for both the complex and the simple version of the English, German and Russian experiment. 
Appendix C

$*$

References

Arnett, N., \& Wagers, M. (2017). Subject encodings and retrieval interference. Journal of Memory and Language, 93, 22-54. https://doi.org/https://doi.org/10.1016/j.jml.2016. 07.005

Avetisyan, S., Lago, S., \& Vasishth, S. (2020). Does case marking affect agreement attraction in comprehension? Journal of Memory and Language, 112, 104087. https://doi.org/https: //doi.org/10.1016/j.jml.2020.104087

Birch, S., \& Rayner, K. (1997). Linguistic focus affects eye movements during reading. Memory E Cognition, 25, 653-660. https://doi.org/https://doi.org/10.3758/bf03211306

Bürkner, P.-C. (2017). brms: An R package for Bayesian multilevel models using Stan. Journal of Statistical Software, $80(1), 1-28$.

Bürkner, P.-C., \& Vuorre, M. (2019). Ordinal regression models in psychology: A tutorial. Advances in Methods and Practices in Psychological Science, 2(1), 77-101. https: //doi.org/10.1177/2515245918823199

Caplan, D., \& Waters, G. S. (1999). Verbal working memory and sentence comprehension. Behavioral and Brain Sciences, 22(1), 77-94. https://doi.org / 10.1017/ S0140525X99001788

Carpenter, B., Gelman, A., Hoffman, M., Lee, D., Goodrich, B., Betancourt, M., Brubaker, M. A., Guo, J., Li, P., \& Riddell, A. (2016). Stan: A probabilistic programming language. Journal of Statistical Software, 20, 1-37.

Chomsky, N. (1971). Deep structure, surface structure and semantic interpretation. In D. D. Steinberg \& L. A. Jakobovits (Eds.), Semantics: An interdisciplinary reader in philosophy, linguistics and psychology (pp. 183-216). Cambridge, Cambridge University Press. 
Clark, H. H. (1973). The language-as-fixed-effect fallacy: A critique of language statistics in psychological research. Journal of Verbal Learning and Verbal Behavior, 12(4), 335-359. https://doi.org/https://doi.org/10.1016/S0022-5371(73)80014-3

Cunnings, I., \& Felser, C. (2013). The role of working memory in the processing of reflexives. Language and Cognitive Processes, 28(1-2), 188-219.

Cunnings, I., \& Sturt, P. (2014). Coargumenthood and the processing of reflexives. Journal of Memory and Language, 75, 117-139.

Cunnings, I., \& Sturt, P. (2018). Retrieval interference and sentence interpretation. Journal of Memory and Language, 102, 16-27.

de Groot, A. (1956/2014). The meaning of "significance" for different types of research [translated and annotated by Eric-Jan Wagenmakers, Denny Borsboom, Josine Verhagen, Rogier Kievit, Marjan Bakker, Angelique Cramer, Dora Matzke, Don Mellenbergh and Han L.J. van der Maas]. Acta Psychologica, 148, 188-194. https://doi.org/https: //doi.org/10.1016/j.actpsy.2014.02.001

Dillon, B. W., Clifton, C., Sloggett, S., \& Frazier, L. (2017). Appositives and their aftermath: Interference depends on at-issue vs. not-at-issue status. Journal of Memory and Language, 96, 93-109. https://doi.org/https://doi.org/10.1016/j.jml.2017.04.008

Dillon, B. W., Mishler, A., Sloggett, S., \& Phillips, C. (2013). Contrasting intrusion profiles for agreement and anaphora: Experimental and modeling evidence. Journal of Memory and Language, 69, 85-103.

Fedorenko, E., Gibson, E., \& Rohde, D. (2006). The nature of working memory capacity in sentence comprehension: Evidence against domain specific resources. Journal of Memory and Language, 54, 541-553.

Ferreira, F., Bailey, K. G. D., \& Ferraro, V. (2002). Good-enough representations in language comprehension. Current Directions in Psychological Science, 11, 11-15.

Freedman, L. S., Lowe, D., \& Macaskill, P. (1984). Stopping rules for clinical trials incorporating clinical opinion. Biometrics, 40(3), 575-586. 
Gelman, A., Carlin, J. B., Stern, H. S., Dunson, D. B., Vehtari, A., \& Rubin, D. B. (2014). Bayesian data analysis (3rd). Boca Raton, FL, Chapman; Hall/CRC.

Gelman, A., \& Carlin, J. (2014). Beyond Power Calculations: Assessing Type S (Sign) and Type M (Magnitude) Errors. Perspectives on Psychological Science, 6(9), 641-651.

Gelman, A., Simpson, D., \& Betancourt, M. (2017). The prior can often only be understood in the context of the likelihood. Entropy, 19(10), 555. https://doi.org/10.3390/e19100555

Gibson, E. (2000). Dependency locality theory: A distance-based theory of linguistic complexity. In A. Marantz, Y. Miyashita, \& W. O’Neil (Eds.), Image, language, brain (pp. 95-126). Cambridge, MA, MIT Press.

Glaser, Y. G., Martin, R. C., Van Dyke, J. A., Hamilton, A. C., \& Tan, Y. (2013). Neural basis of semantic and syntactic interference in sentence comprehension. Brain and language, 126 (3), 314-326. https://doi.org/https://doi.org/10.1016/j.bandl.2013.06.006

Gordon, P. C., Hendrick, R., \& Johnson, M. (2001). Memory interference during language processing. Journal of Experimental Psychology: Learning, Memory, and Cognition, $27(6), 1411-1423$.

Gordon, P. C., Hendrick, R., \& Johnson, M. (2004). Effects of noun phrase type on sentence complexity. Journal of Memory and Language, 51(1), 97-114. https://doi.org/https: //doi.org/10.1016/j.jml.2004.02.003

Gordon, P. C., Hendrick, R., Johnson, M., \& Lee, Y. (2006). Similarity-based interference during language comprehension: Evidence from eye tracking during reading. Journal of experimental psychology: Learning, memory, and cognition, 32(6), 1304-1321. https: //doi.org/https://doi.org/10.1037/0278-7393.32.6.1304

Gordon, P. C., Hendrick, R., \& Levine, W. H. (2002). Memory-load interference in syntactic processing. Psychological Science, 13(5), 425-430.

Gronau, Q. F., Sarafoglou, A., Matzke, D., Ly, A., Boehm, U., Marsman, M., Leslie, D. S., Forster, J. J., Wagenmakers, E.-J., \& Steingroever, H. (2017). A tutorial on bridge sampling. Journal of Mathematical Psychology, 81, 80-97. 
Gronau, Q. F., Singmann, H., \& Wagenmakers, E.-J. (2017). Bridgesampling: An R Package for Estimating Normalizing Constants.

Hartsuiker, R. J., Schriefers, H. J., Bock, K., \& Kikstra, G. M. (2003). Morphophonological influences on the construction of subject-verb agreement. Memory and Cognition, 31, 1316-1326. https://doi.org/https://doi.org/10.3758/BF03195814

Hobbs, B. P., \& Carlin, B. P. (2008). Practical Bayesian design and analysis for drug and device clinical trials. Journal of Biopharmaceutical Statistics, 18(1), 54-80.

Jäger, L. A., Engelmann, F., \& Vasishth, S. (2015). Retrieval interference in reflexive processing: Experimental evidence from Mandarin, and computational modeling. Frontiers in Psychology, 6(617).

Jäger, L. A., Engelmann, F., \& Vasishth, S. (2017). Similarity-based interference in sentence comprehension: Literature review and Bayesian meta-analysis. Journal of Memory and Language, (94), 316-339.

Jäger, L. A., Mertzen, D., Van Dyke, J. A., \& Vasishth, S. (2020). Interference patterns in subject-verb agreement and reflexives revisited: A large-sample study. Journal of Memory and Language, 111. https://doi.org/https://doi.org/10.1016/j.jml.2019.104063

Jeffreys, H. (1961). Theory of probability. Oxford, Clarendon Press.

Just, M. A., \& Carpenter, P. A. (1992). A capacity theory of comprehension: Individual differences in working memory. Psychological Review, 99, 122-149. https://doi.org/ https://doi.org/10.1037/0033-295X.99.1.122

Kass, R. E., \& Raftery, A. E. (1995). Bayes factors. Journal of the American Statistical Association, 90(430), 773-795. https://doi.org/10.1080/01621459.1995.10476572

Keshev, M., \& Meltzer-Asscher, A. (2019). Distant relatives: Resumptive pronouns can inherit agreement features of implied antecedents, In 32nd annual cuny conference on human sentence processing. 
Koesterich, N., Keshev, M., Shamai, D., \& Meltzer-Asscher, A. (2021). Interference in the comprehension of filler-gap and filler-resumptive dependencies, In 34th annual cuny conference on human sentence processing.

Kruschke, J. (2015). Doing Bayesian data analysis: A tutorial with R, JAGS, and Stan (2nd ed.). Amsterdam, Academic Press.

Kush, D., Johns, C. L., \& Van Dyke, J. A. (2019). Prominence-sensitive pronoun resolution: New evidence from the speed-accuracy tradeoff procedure. Journal of Experimental Psychology: Learning, Memory, and Cognition, 45(7), 1234-1251. https://doi.org/ https://doi.org/10.1037/xlm0000646

Lago, S., Shalom, D. E., Sigman, M., Lau, E. F., \& Phillips, C. (2015). Agreement attraction in spanish comprehension. Journal of Memory and Language, 82, 133-149. https: //doi.org/https://doi.org/10.1016/j.jml.2015.02.002

Laurinavichyute, A., Jäger, L. A., Akinina, Y., Roß, J., \& Dragoy, O. (2017). Retrieval and encoding interference: Cross-linguistic evidence from anaphor processing. Frontiers in Psychology, 8, 965. https://doi.org/https://doi.org/10.3389/fpsyg.2017.00965

Laurinavichyute, A., \& von der Malsburg, T. (2021a). Agreement attraction in grammatical sentences arises only in the good-enough processing mode, In 34 th annual cuny conference on human sentence processing.

Laurinavichyute, A., \& von der Malsburg, T. (2021b). Semantic attraction in sentence comprehension [submitted]. submitted. https://doi.org/10.31234/osf.io/hk9nc

Lee, M. D., \& Wagenmakers, E.-J. (2014). Bayesian cognitive modeling: A practical course. Cambridge, Cambridge University Press. https://doi.org/10.1017/CBO9781139087759 Lewandowski, D., Kurowicka, D., \& Joe, H. (2009). Generating random correlation matrices based on vines and extended onion method. Journal of Multivariate Analysis, 100(9), 1989-2001. 
Lewandowsky, S., Geiger, S. M., \& Oberauer, K. (2008). Interference-based forgetting in verbal short-term memory. Journal of Memory and Language, 59(2), 200-222. https: //doi.org/https://doi.org/10.1016/j.jml.2008.04.004

Lewis, R. L. (2000). Specifying architectures for language processing: Process, control, and memory in parsing and interpretation. In M. W. Crocker, M. Pickering, \& C. Clifton Jr. (Eds.), Architectures and Mechanisms for Language Processing (pp. 56-89). Cambridge, Cambridge University Press.

Lewis, R. L., \& Vasishth, S. (2005). An activation-based model of sentence processing as skilled memory retrieval. Cognitive Science, 29(3), 375-419.

Logačev, P., \& Vasishth, S. (2013). Em2: A package for computing reading time measures for psycholinguistics [R package version 0.9]. R package version 0.9. https://cran.rproject.org/src/contrib/Archive/em2/

Logačev, P., \& Vasishth, S. (2016). A multiple-channel model of task-dependent ambiguity resolution in sentence comprehension. Cognitive Science, 40(2), 266-298. https://doi. org $/ 10.1111 / \operatorname{cogs} .12228$

Lowder, M., \& Gordon, P. C. (2014). Effects of animacy and noun-phrase relatedness on the processing of complex sentences. Memory \& Cognition, 42, 794-805. https: //doi.org/https://doi.org/10.3758/s13421-013-0393-7

MacLeod, C. M., Gopie, N., Hourihan, K. R., K. L. Neary, \& Ozubko, J. D. (2010). The production effect: Delineation of a phenomenon. Journal of Experimental Psychology: Learning, Memory, and Cognition, 36(3), 671-685. https://doi.org/https://doi.org/ $10.1037 / \mathrm{a} 0018785$

McElree, B. (2000). Sentence comprehension is mediated by content-addressable memory structures. Journal of Psycholinguistic Research, 29(2), 111-123.

Miller, G. A. (1962). Some psychological studies of grammar. American Psychologist, 17, $748-762$. 
Miller, G. A., \& Chomsky, N. (1963). Finitary models of language users. In R. D. Luce, R. R. Bush, \& E. Galanter (Eds.), Handbook of mathematical psychology (pp. 419-491). New York, NY, John Wiley; Sons.

Mulder, J., \& Wagenmakers, E.-J. (2016). Editors' introduction to the special issue: "Bayes factors for testing hypotheses in psychological research: Practical relevance and new developments". Journal of Mathematical Psychology, 72, 1-5. https://doi.org/https: //doi.org/10.1016/j.jmp.2016.01.002

Ness, T., \& Meltzer-Asscher, A. (2017). Working memory in the processing of long-distance dependencies: Interference and filler maintenance. Journal of Psycholinguistic Research, (46), 1353-1365. https://doi.org/https://doi.org/10.1007/s10936-017-9499-6

Nicenboim, B., Schad, D. J., \& Vasishth, S. (2021). An introduction to bayesian data analysis for cognitive science. https://vasishth.github.io/bayescogsci/book/

Nicenboim, B., Vasishth, S., Engelmann, F., \& Suckow, K. (2018). Exploratory and confirmatory analyses in sentence processing: A case study of number interference in German. Cognitive Science, 42. https://doi.org/10.1111/cogs.12589

Nicenboim, B., Vasishth, S., \& Rösler, F. (2020). Are words pre-activated probabilistically during sentence comprehension? evidence from new data and a bayesian randomeffects meta-analysis using publicly available data. Neuropsychologia, 142, 107427. https://doi.org/https://doi.org/10.1016/j.neuropsychologia.2020.107427

Nicol, J., \& Antón-Méndez, I. (2009). Time and again: Theoretical perspectives on formal linguistics in honor of D. Terence Langendoen. In W. Lewis, S. Karimi, H. Harley, \& S. Farrer (Eds.). Amsterdam, John Benjamins Publishing.

Nieuwland, M. S., Politzer-Ahles, S., Heyselaar, E., Segaert, K., Darley, E., Kazanina, N., Zu Wolfsthurn, S. V. G., Bartolozzi, F., Kogan, V., Ito, A., Mézière, D., Barr, D., Rousselet, G. A., Ferguson, H. J., Busch-Moreno, S., Fu, X., Tuomainen, J., Kulakova, E., Husband, E. M., ... Huettig, F. (2018). Large-scale replication study reveals a limit on probabilistic prediction in language comprehension. eLife, 7, e33468. 
Oberauer, K., \& Kliegl, R. (2006). A formal model of capacity limits in working memory. Journal of Memory and Language.

Parker, D., \& Phillips, C. (2017). Reflexive attraction in comprehension is selective. Journal of Memory and Language, 94, 272-290.

Quinlan, C. K., \& Taylor, T. L. (2013). Enhancing the production effect in memory. Memory, 21 (8), 904-915. https://doi.org/10.1080/09658211.2013.766754

Rabe, M., Vasishth, S., Hohenstein, S., Kliegl, R., \& Schad, D. (2020). Hypr: An R package for hypothesis-driven contrast coding. The Journal of Open Source Software, 5, 2134. https://doi.org/10.21105/joss.02134

Rayner, K. (1998). Eye movements in reading and information processing: 20 years of research. Psychological Bulletin, 124, 372-422.

Rich, S., \& Wagers, M. (2020). Semantic similarity and temporal contiguity in subject-verb dependency processing, In 33rd annual cuny conference on human sentence processing.

Rouder, J. N., Haaf, J., \& Vandekerckhove, J. (2018). Bayesian inference for psychology, part IV: Parameter estimation and Bayes factors. Psychonomic Bulletin \& Review, 25, 102-113. https://doi.org/https://doi.org/10.3758/s13423-017-1420-7

Schad, D. J., Nicenboim, B., Bürkner, P.-C., Betancourt, M., \& Vasishth, S. (2021). Workflow techniques for the robust use of bayes factors.

Schlueter, Z., Parker, D., \& Lau, E. (2019). Error-driven retrieval in agreement attraction rarely leads to misinterpretation. Frontiers in Psychology, 10, 1002. https://doi.org/ $10.3389 /$ fpsyg.2019.01002

Simons, D. J., Shoda, Y., \& Lindsay, D. S. (2017). Constraints on generality (cog): A proposed addition to all empirical papers. Perspectives on Psychological Science, 12(6), 11231128. https://doi.org/10.1177/1745691617708630

Sinharay, S., \& Stern, H. S. (2002). On the sensitivity of Bayes factors to the prior distributions. The American Statistician, 56(3), 196-201. https://doi.org/10.1198/000313002137 
Smith, G., \& Vasishth, S. (2020). A principled approach to feature selection in models of sentence processing. Cognitive science, 44 12, e12918.

Spiegelhalter, D. J., Freedman, L. S., \& Parmar, M. K. (1994). Bayesian approaches to randomized trials. Journal of the Royal Statistical Society. Series A (Statistics in Society), $157(3), 357-416$.

Sturt, P. (2003). The time-course of the application of binding constraints in reference resolution. Journal of Memory and Language, 48, 542-562.

Swets, B., Desmet, T., Clifton, C., \& Ferreira, F. (2008). Underspecification of syntactic ambiguities: Evidence from self-paced reading. Memory and Cognition, 36(1), 201-216.

Thornton, R., \& MacDonald, M. C. (2003). Plausibility and grammatical agreement. Journal of Memory and Language, 48(4), 740-759. https://doi.org/https://doi.org/10.1016/ S0749-596X(03)00003-2

Van Dyke, J. A. (2007). Interference effects from grammatically unavailable constituents during sentence processing. Journal of Experimental Psychology. Learning, Memory, and Cognition, 33(2), 407-430.

Van Dyke, J. A., Johns, C. L., \& Kukona, A. (2014). Low working memory capacity is only spuriously related to poor reading comprehension. Cognition, 131 (3), 373-403. https://doi.org/https://doi.org/10.1016/j.cognition.2014.01.007

Van Dyke, J. A., \& Lewis, R. L. (2003). Distinguishing effects of structure and decay on attachment and repair: A cue-based parsing account of recovery from misanalyzed ambiguities. Journal of Memory and Language, 49, 285-316.

Van Dyke, J. A., \& McElree, B. (2006). Retrieval interference in sentence comprehension. Journal of Memory and Language, 55(2), 157-166.

Van Dyke, J. A., \& McElree, B. (2011). Cue-dependent interference in comprehension. Journal of Memory and Language, 65(3), 247-263.

Vasishth, S. (2019). Power plot [Available under a CC-BY4.0 license]. https://doi.org/https: //doi.org/10.6084/m9.figshare.10281905.v1 
Vasishth, S., \& Lewis, R. L. (2006). Argument-head distance and processing complexity: Explaining both locality and antilocality effects. Language, 82(4), 767-794.

Vasishth, S., Mertzen, D., Jäger, L. A., \& Gelman, A. (2018). The statistical significance filter leads to overoptimistic expectations of replicability. Journal of Memory and Language, 103, 151-175. https://doi.org/https://doi.org/10.1016/j.jml.2018.07.004

Wagers, M. W., Lau, E. F., \& Phillips, C. (2009). Agreement attraction in comprehension: Representations and processes. Journal of Memory and Language, 61, 206-237.

Ward, P., \& Sturt, P. (2007). Linguistic focus and memory: An eye movement study. Memory E Cognition, 35, 73-86. https://doi.org/https://doi.org/10.3758/bf03195944

Yarkoni, T. (2019). The generalizability crisis. https://doi.org/10.31234/osf.io/jqw35 